\title{
Solvent-Free Digital Light 3D Printing using Biodegradable Polymeric Photoinitiators
}

\author{
Matthias Sandmeier, ${ }^{\#[a]}$ Nevena Paunović,,$\left[\right.$ [a] Riccardo Conti, ${ }^{[b]}$ Leopold Hofmann, ${ }^{[a]}$ Jieping Wang, ${ }^{[b]}$ \\ Zhi Luo, ${ }^{[\mathrm{a}]}$ Kunal Masania, ${ }^{[\mathrm{c}, \mathrm{d}]} \mathrm{Na} \mathrm{Wu},{ }^{[\mathrm{e}]}$ Nicole Kleger ${ }^{[\mathrm{c}]}$ Fergal Brian Coulter, ${ }^{[\mathrm{c}]}$ André R. Studart, ${ }^{[\mathrm{c}]}$ \\ Hansjörg Grützmacher, ${ }^{[b]}$ Jean-Christophe Leroux ${ }^{*[a]}$, Yinyin Bao*[a]
}

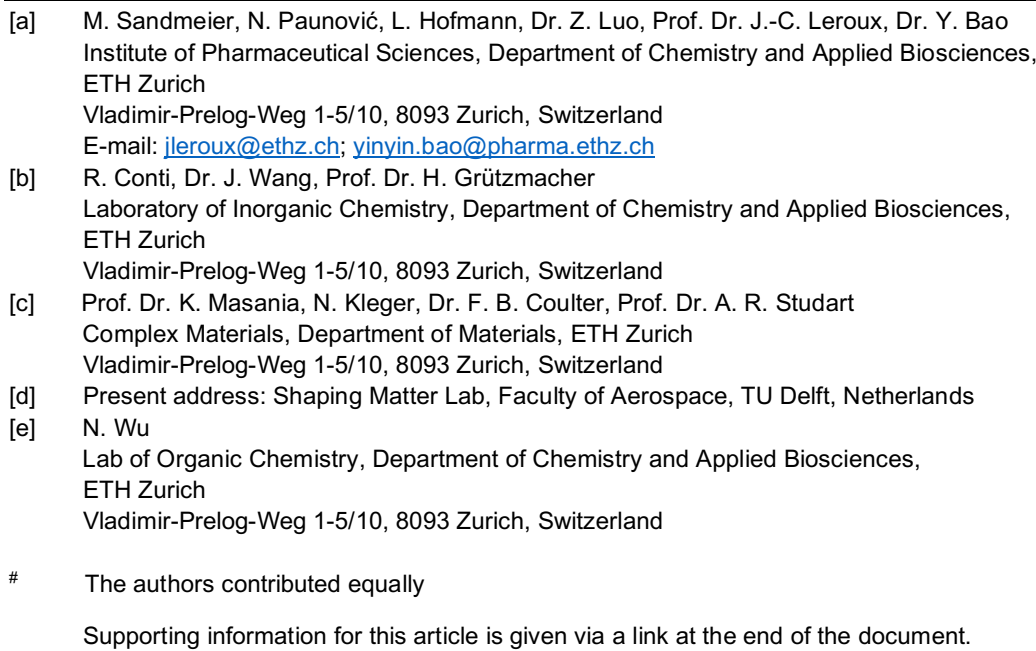

\begin{abstract}
Vat photopolymerization 3D printing provides new opportunities for the fabrication of tissue scaffolds and medical devices. However, it usually requires the use of organic solvents or diluents to dissolve the solid photoinitators, making this process environmentally unfriendly, and not optimal for biomedical applications. Here, we report biodegradable liquid polymeric photoinitiators for solvent-free 3D printing of biodegradable polymeric materials by digital light processing. These photoinitiators enable systematic investigation of structure-property relationship of 3D printing polymeric materials without the interference from the reactive diluents and offer new perspectives for the solvent-free 3D additive manufacturing of bioresorbable medical implants as well as other functional devices.
\end{abstract}

Additive manufacturing, or commonly called $3 \mathrm{D}$ printing, is attracting great attention due to its ability to create $3 \mathrm{D}$ geometries with precise macro and microarchitectures. ${ }^{[1]}$ In combination with computer-assisted design and medical imaging techniques, it has enormous potential in the biomedical field for applications including tissue engineering, ${ }^{[2-4]}$ drug delivery, ${ }^{[5-7]}$ soft robotics, ${ }^{[8-10]}$ and for the fabrication of medical devices. ${ }^{[11-14]}$ Among the existing $3 \mathrm{D}$ printing techniques, vat photopolymerization is endowed with high resolution and good surface quality, which are highly desired in manufacturing of complex objects, such as personalized medical devices. ${ }^{[15,16]}$ With stereolithography (SLA) and digital light processing (DLP) as the best-known examples, vat photopolymerization $3 \mathrm{D}$ printing is based on a localized UV radiation-triggered photocrosslinking process, that takes place in a vat containing a liquid resin made of (macro)monomers and a photoinitiator. Through layer-by-layer crosslinking of the (macro)monomers, which is typically triggered by the photolysis of the photoinitiator into the primary radicals, the photocurable resin is converted to a solid product. ${ }^{[17,18]}$ Owing to its great advantages, the last ten years have witnessed the fast development of vat photopolymerization 3D printing in terms of both techniques and materials used. ${ }^{[19-26]}$

Despite the benefits of SLA, DLP and their advanced editions, ${ }^{[27-29]}$ some caveats remain, especially when the manufacturing of bioresorbable medical devices is sought. ${ }^{[30-32]}$ The main drawbacks include the necessity of adding organic solvents or diluents and the use of potentially cytotoxic photoinitiators. ${ }^{[11-13,31-34]}$ Conventional biodegradable 3D printing macromonomers, such as methacrylated poly(lactide) (PLA), ${ }^{[35,36]}$ poly(e-caprolactone) (PCL) $)^{[37-39]}$ and poly(propylene fumarate), ${ }^{[4-42]}$ are thermoplastic polymers that are in the solid state at ambient temperature due to their high glass transition temperature $\left(T_{g}\right)$ and/or melting point. To achieve the low resin viscosity $(1-5 \mathrm{mPa} \cdot \mathrm{s})$ required for vat photopolymerization 3D printing, $30-50 \mathrm{wt} \%$ of reactive diluents are usually added to the macromonomers. ${ }^{[35-42]}$ Moreover, organic solvents, including both non-reactive and reactive diluents, are used to dissolve the photoinitiator molecules in order to homogeneously mix them with the macromonomers. However, removing the organic solvents (e.g., $\mathrm{CHCl}_{3}$ ) before the printing process carries the risk of undesired premature crosslinking, while post-printing removal causes a shrinkage of the object that can negatively impact its mechanical properties. Furthermore, the addition of reactive diluents can change the structure of the crosslinked network and its crosslinking density, thus significantly influencing the mechanical properties and degradability of the $3 \mathrm{D}$ printed devices. ${ }^{[31,34-42]}$ Moreover, the photoinitiators often used for 3D printing (e.g., phenylbis(2,4,6-trimethylbenzoyl)phosphine oxide), and their byproducts are usually cytotoxic upon UV irradiation, raising potential safety concerns. ${ }^{[43-46]}$. 
Recently, grafting photoinitiating groups onto polymer chains has become an effective way to decrease the amount of potentially toxic products in the photopolymerization systems. The resulting polymeric photoinitiators exhibited lower toxicity and better chemical compatibility with the macromonomers. ${ }^{[45,46]}$ However, there are only a few polymeric photoinitiators exploited for 3D printing by vat photopolymerization, and they are only used to prepare hydrogels or solvent-rich resins. ${ }^{[47-49]}$ This is likely due to the fact that the current polymeric photoinitiators are all in solid state, and therefore unsuitable for the preparation of a solventfree resin. We hypothesized that a polymeric photoinitiator that is liquid under ambient conditions, would allow solvent-free photopolymerization 3D printing by simply mixing the photoinitiator with suitable macromonomers. By covalent linkage of the photoinitiator to a biodegradable polymer chain with structural similarity to the macromonomers, the preparation and $3 \mathrm{D}$ printing of the photocurable resin can be both conducted without the addition of any organic solvent or reactive diluent. This may greatly expand the space to enhance the mechanical performance of $3 \mathrm{D}$ printed biodegradable elastomers.

To enable the preparation of suitable polymeric photoinitiators, two derivatives of bisacylphosphane oxide (BAPO) functionalized with 2-hydroxyethyl acrylate (HEA) or 2,3-dihydroxypropyl acrylate (DIOL-A) were synthesized according to reported methods. ${ }^{[48,50]}$ Hereafter these are named BAPO-HEA and BAPODIOL, respectively, and their structural formulas are shown in Scheme 1. These two compounds were subsequently used as the initiators for ring-opening polymerization of a mixture of $D, L$-lactide (DLLA) and $\varepsilon$-caprolactone (CL), which led to two welldefined BAPO polymers with a single or two polymer chains (supporting information, Figures S1-S6). As shown in Table 1, the resulting polymers, BAPO-HEA-poly(DLLA-co-CL) (P1) and BAPO-DIOL-poly(DLLA-co-CL) (P2), had molecular weight (MW) of $1990 \mathrm{~g} \mathrm{~mol}^{-1}$ and $2360 \mathrm{~g} \mathrm{~mol}^{-1}$ by ${ }^{1} \mathrm{H}$ NMR, respectively (see Table 1 and supporting information).

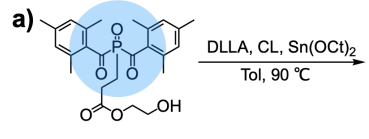

BAPO-HEA

b)

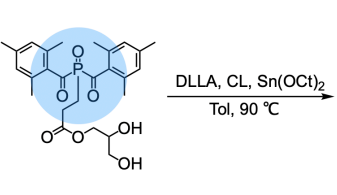

BAPO-DIOL

c)

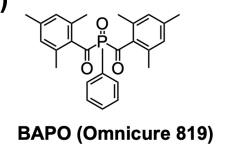

d)

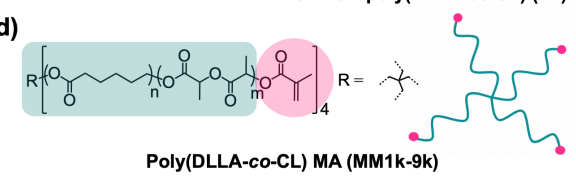

Scheme 1. a) Synthesis of BAPO-HEA-poly(DLLA-co-CL) (P1) from BAPOHEA by random copolymerization of DLLA and CL (P1); b) Synthesis of BAPODIOL-poly(DLLA-co-CL) (P2) from BAPO-DIOL by random copolymerization of DLLA and $\mathrm{CL} ; \mathrm{c}$ ) Chemical structure of a commercially available BAPO (Omnicure 819); d) Chemical structure of the macromonomer poly(DLLA-Co-CL) MA (MM1k-9k) used for 3D printing.
Owing to the amorphous nature of the attached random copolymer chains, both polymers were liquid at room temperature, with $\mathrm{T}_{\mathrm{g}}$ of $-33.7^{\circ} \mathrm{C}$ and $-26.5^{\circ} \mathrm{C}$, respectively (Figure 1a). This is consistent with previous reports ${ }^{[51-52]}$ and our recent work ${ }^{[53]}$ on random copolymers. The light absorption of the BAPO polymers was measured in THF $(0.1 \mathrm{mM})$ and compared to the commercial BAPO photoinitiator (Omnicure 819 , with previous trade name Irgacure 819). Both BAPO polymers showed strong absorption in the range of $360-450 \mathrm{~nm}$, similar to BAPO (Figure $1 \mathrm{~b}$ ). Different from their non-polymeric counterpart, the BAPO polymers had the same level of absorption in the visible-light $(>400 \mathrm{~nm})$ and the UV-light region. Consequently, P1 and P2 should efficiently generate radicals under visible LED light irradiation, initiate radical polymerization reactions, and hence enable DLP 3D printing.

To evaluate the 3D printing ability of the BAPO polymers, we synthesized a series of biodegradable macromonomers with $\mathrm{Mn}_{\mathrm{n}, \mathrm{NMR}}$ ranging from 1200 to $9100 \mathrm{~g} \mathrm{~mol}^{-1}$ (MM1k-9k) by copolymerizing DLLA and CL, with subsequent methacrylation to introduce the crosslinkable moieties (Scheme 1, Figures S7 and S8), ${ }^{[53]}$ and tested the miscibility of the BAPO polymers with the macromonomers. As shown in Figure 1c, the mixture of $\mathrm{P} 1$ and the macromonomers, produced a transparent solvent-free photoresin. In contrast, the commercial BAPO photoinitiator remained suspended in the resin, even after $1 \mathrm{~h}$ of sonication at $60^{\circ} \mathrm{C}$.
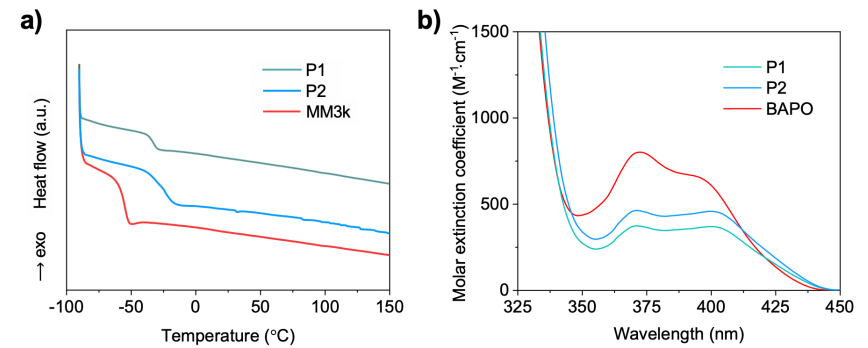

c)
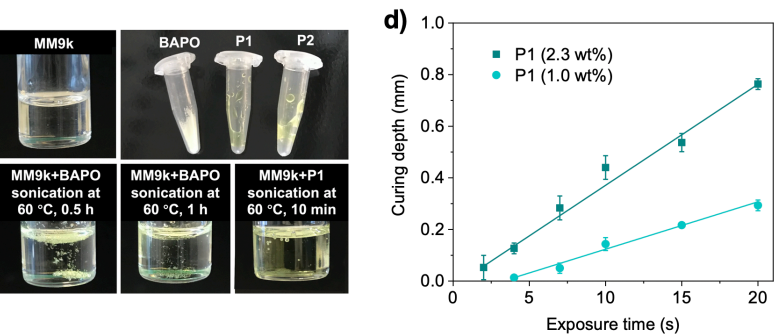

e)

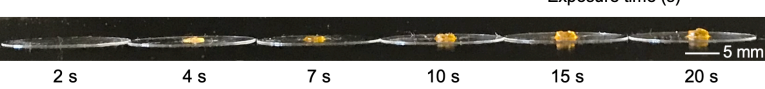

Figure 1. a) Differential scanning calorimetry (DSC) curves of MM3k (3000 g $\mathrm{mol}^{-1}$ ) and BAPO polymers; b) Absorption spectra of BAPO and BAPO polymers in THF (0.1 mM eq. BAPO); c) Photographs of MM9k, BAPO, BAPO polymers and the resins containing BAPO or $\mathrm{P} 1$. d) Curing depth-exposure time relationship of the resin with $\mathrm{P} 1-\mathrm{MM} 9 \mathrm{k}$. The curing depth is expressed as mean \pm s.d. $(n=3)$. The light intensity was $25.67 \mathrm{~mW} / \mathrm{cm}^{2}$; e) Photograph of the crosslinked materials (P1-MM9k with $2.3 \mathrm{wt} \% \mathrm{P} 1$ ) after various exposure times (side view). Sudan I was added in P1-MM9k resin as a UV absorber.

To determine the characteristic penetration depth of the resins, we measured the curing depth (thickness of polymerized resin) of poly(DLLA-Co-CL) MA in the presence of BAPO polymers, after different DLP laser exposure times (Figure 1d,e). As shown in 
Figure 1d, the curing depth of MM9k with 2.3 wt\% P1 gradually increased from 50 to $750 \mu \mathrm{m}$ with the increase of the exposure time from 2 to $20 \mathrm{~s}$. The characteristic penetration depth of P1-MM9k resin was determined to be $385 \mu \mathrm{m}$ (Figure S9). ${ }^{[14]}$ When the $\mathrm{P} 1$ concentration was decreased to $1.0 \mathrm{wt} \%$, the penetration depth was reduced to $157 \mu \mathrm{m}$. The curing test was also performed with $\mathrm{P} 2-\mathrm{MM} 7 \mathrm{k}$, producing results similar to $\mathrm{P} 1$
(Figure S10a). Attenuated total reflectance-Fourier transform infrared (ATR-FTIR) spectroscopy analysis of P1-MM1k-9k resins before and after $3 \mathrm{D}$ printing, revealed the high conversion of double bonds of the macromonomers (>90\%) for all compositions (Figure S11). This confirms that the light absorption capability of the polymeric photoinitiators is sufficient to initiate the polymerization process for $3 \mathrm{D}$ printing.

Table 1. The characterization of BAPO polymers.

\begin{tabular}{ccccccc}
\hline BAPO polymer & $M_{\mathrm{n}, \mathrm{NMR}}{ }^{[\mathrm{a}]}\left(\mathrm{g} \mathrm{mol}^{-1}\right)$ & $\mathrm{DP}_{\mathrm{LA}}{ }^{[\mathrm{a}]}$ & $\mathrm{DP}_{\mathrm{CL}}{ }^{[\mathrm{a}]}$ & $\mathrm{T}_{\mathrm{g}}^{[\mathrm{b}]}\left({ }^{\circ} \mathrm{C}\right)$ & $\lambda_{\mathrm{abs}}{ }^{[\mathrm{c}]}(\mathrm{nm})$ & $\begin{array}{c}\mathrm{BAPO} \mathrm{content} \\
(\mathrm{wt} \%)\end{array}$ \\
\hline $\mathrm{P} 1$ & 1990 & 3.5 & 9 & -33.7 & 371,402 & 23.0 \\
$\mathrm{P} 2$ & 2360 & 5.5 & 9.5 & -26.5 & 371,401 & 20.7 \\
\hline
\end{tabular}

[a] Degree of polymerization (DP) calculated from the ratio of the areas under the peak of DLLA (proton - $\mathrm{CH}-$ ), $\mathrm{CL}$ (proton -COOCH - ) and BAPO (aromatic protons). $M_{\mathrm{n}, \mathrm{NMR}}=\mathrm{MW} \mathrm{WAPO}_{\mathrm{B}}+\mathrm{MW} \mathrm{LA}_{\mathrm{LA}} \times \mathrm{DP}_{\mathrm{LA}}+\mathrm{MW}_{\mathrm{CL}} \times \mathrm{DP}_{\mathrm{CL}}$. [b] Determined by DSC. [c] Determined by spectrophotometry. [d] Calculated from the ratio of MW of BAPO-HEA or BAPO-DIOL and the corresponding polymer $M_{\mathrm{n}, \mathrm{NMR}}$.

The performance of the polymeric photoinitiators was evaluated by printing a $\mathrm{NaCl}$ crystal model with P1-MM7k on a DLP 3D printer equipped with a heating system operating at $80-90{ }^{\circ} \mathrm{C}$ (Figure 2a). The 3D printed crystal lattice showed high resolution and smooth surface (Figure $2 \mathrm{~b}$ ). Notably, the equivalent BAPO content in the $3 \mathrm{D}$ printing resin was only ca. $0.5 \mathrm{wt} \%$, which is lower than the usual concentration of conventional photoinitiators (1.0-4.0 wt\%). ${ }^{[30-42]}$ The photoinitiator P2 enabled equally high quality DLP 3D printing (Figure S10b). Tensile test revealed that the mechanical properties of the printed materials were highly dependent on the polymer chain length (Figure 2c,d). When $M_{\mathrm{n}, \mathrm{NMR}}$ increased from 1200 to $9100 \mathrm{~g} \mathrm{~mol}^{-1}$, the Young's modulus (Figure 2d) decreased from 94 to $1.0 \mathrm{MPa}$ and the tensile strength (Figure 2c) decreased from 5.0 to $1.0 \mathrm{MPa}$. This was accompanied by an increase in strain at break from 10 to $80 \%$ (Figure 2d). Molecular weight-dependent compressive resistance was also observed on 3D printed stent-mimicking tubular specimens (Figure 2e). The ones prepared with MM1k showed the highest rigidity while the highest flexibility was obtained with the MM9k resin. These results indicate that our polymeric photoinitiators offer an attractive platform to control the properties of the printed polymers and to systematically investigate their structure-property relationships without the interference of the reactive diluents commonly used in SLA or DLP 3D printing of biodegradable polymers. ${ }^{[31,34]}$ a)

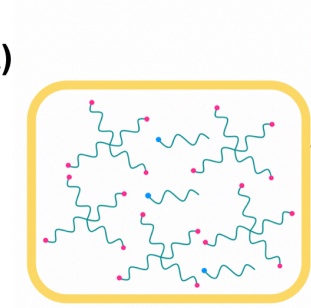

3D printing resin containing
polymeric photoinitiators and macromonomers

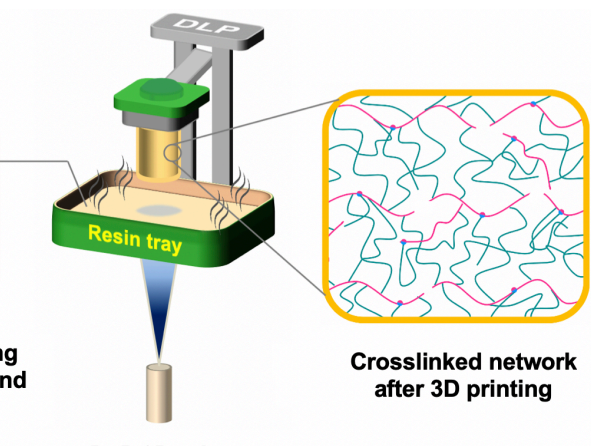

DLP 3D printer b)

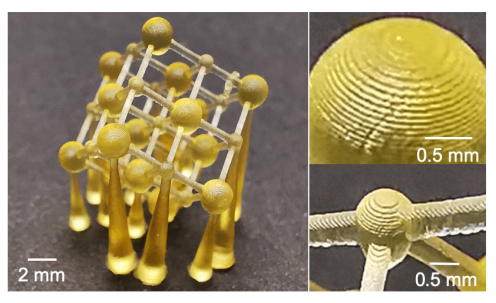

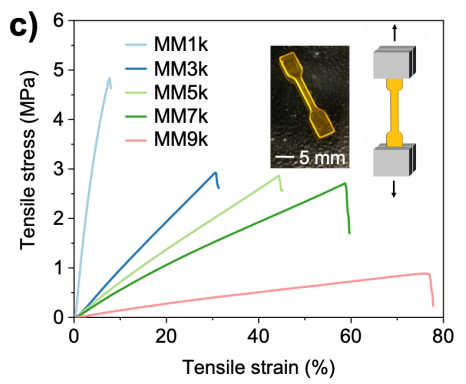

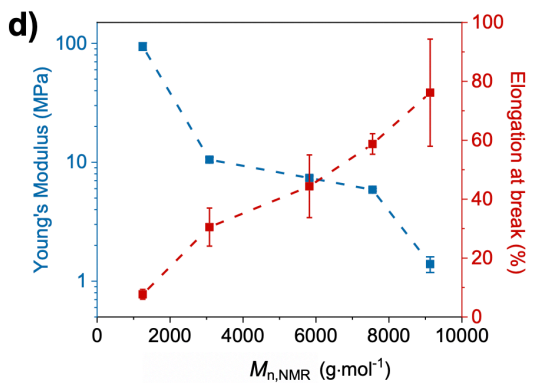

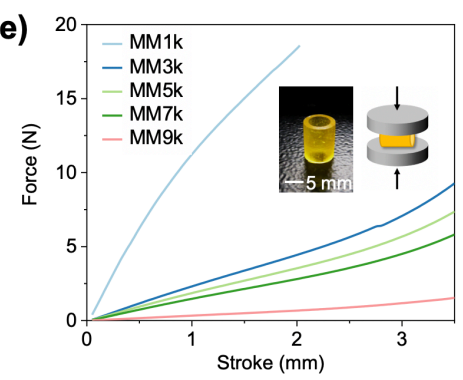


Figure 2. a) Schematic illustration of 3D printing of biodegradable photopolymers by DLP in the presence of polymeric photoinitiators (the digital micromirror device is not shown for simplification); b) Photograph of a 3D printed model of $\mathrm{NaCl}$ crystal with supports, and the zoomed area of the balls representing $\mathrm{Cl}^{-}$and $\mathrm{Na}^{+}$while the connecting rods representing the ionic bonds; $c$ ) Representative stress-strain curves from the tensile test based on 3D printed specimens of poly(DLLA-co-CL) MA with various MWs using P1 as the photoinitiator. Inset: photographs of representative dog-bone shaped specimens; $d$ ) Young's modulus and maximal elongation as a function of the $M_{n, N M R}$ of the macromonomers. The mechanical properties were obtained from the tensile tests and are expressed as mean \pm s.d. ( $n=8$ ); e) Representative force-stroke curves from compression test based on 3D printed specimens of poly(DLLA-co-CL) MA with various MWs using P1 as the photoinitiator. Inset: photographs of representative tubular specimens.

To further study the influence of MW on the degradation profile of the 3D printed macromonomers, we monitored the water uptake, weight loss, and change in compressive resistance of the tubular specimens incubated in PBS $\left(\mathrm{pH} \mathrm{7.4)}\right.$ at $50{ }^{\circ} \mathrm{C}$ over time. As shown in Figure $3 a$, the water uptake of the specimens increased with time, reflecting the increase in hydrophilicity of the polymer matrix occurring upon degradation. Polymers with longer chains were associated with higher water uptake due to the lower crosslinking density and thus higher water permeability. ${ }^{[54]}$ Consequently, the tubular objects prepared with higher MW macromonomers degraded faster (e.g., P1-MM7k showed 55\% of weight loss vs. $\sim 10 \%$ for P1-MM1k after 10 weeks) (Figure $3 \mathrm{~b}, \mathrm{c}$ ), with the P1-MM9k specimen collapsing already at week 8 . As expected, all $3 \mathrm{D}$ printed tubular specimens exhibited a continuous decrease in compressive resistance during the degradation process (Figure S13),
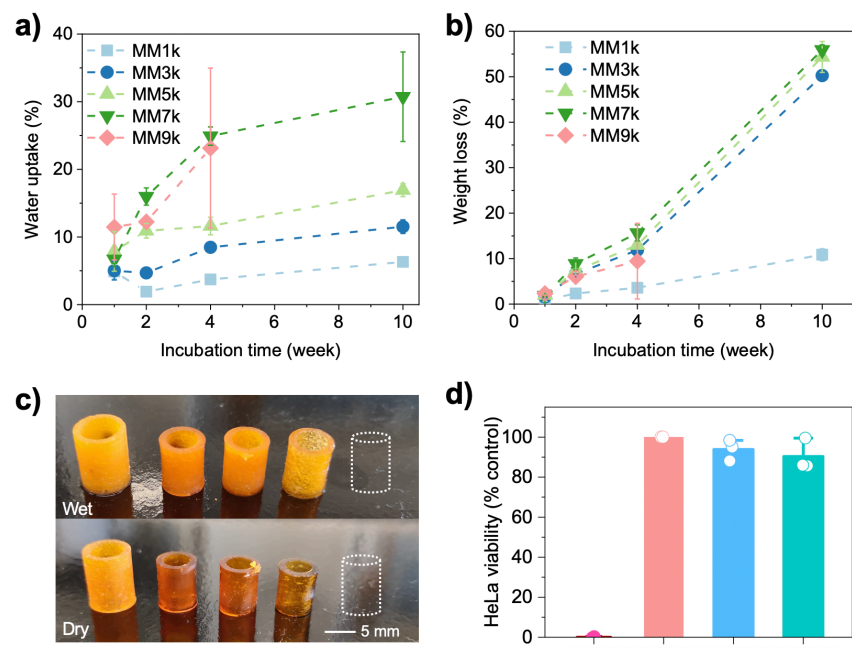

MM1k MM3k MM5k MM7k MM9k

d)

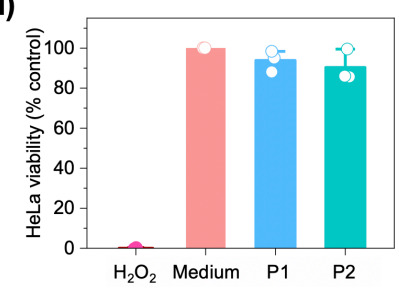

Figure 3. a-c) Degradation study of $3 D$ printed tubular specimens from poly(DLLA-co-CL) MA with various $\mathrm{MWs}$ using $\mathrm{P} 1$ as the photoinitiator $\left(50^{\circ} \mathrm{C}\right.$ in PBS pH 7.4). a) Water uptake over the incubation time; b) Weight loss depending on the incubation time. All data are expressed as mean \pm s.d. ( $n=$ 4); c) Photographs of the tubular specimens from P1-MM1k-9k after 10 weeks of incubation. The P1-MM9k specimens collapsed at week 8; d) HeLa cell viability after 48 -h incubation $\left(37^{\circ} \mathrm{C}\right.$ ) with P1-MM9k (blue) and P2-MM7k (green) 3D printed discs determined by MTS assay relative to the negative control (cell culture medium, pink). Positive control $\left(10 \mathrm{mM} \mathrm{H}_{2} \mathrm{O}_{2}\right)$ is presented with a purple bar. Mean + SD $(n=3)$.

To assess cytocompatibility, the 3D printed discs from P1-MM9k and P2-MM7k were incubated with HeLa cells on the top of Transwell ${ }^{\circledR}$ inserts ${ }^{[55]}$ and cell viability was determined by the MTS assay after $48 \mathrm{~h}$ of incubation. As shown in Figure $3 \mathrm{~d}$, the printed disks did not exhibit significant in vitro cytotoxicity under the tested conditions.
To further illustrate the wide applicability of polymeric BAPO photoinitiators, we 3D printed by DLP a shape memory object using $\mathrm{PCL}$ methacrylate (PCLMA, $8300 \mathrm{~g} \mathrm{~mol}^{-1}$, Figure $\mathrm{S} 14)^{[39,56,57]}$ and $\mathrm{P} 1$. A complex object with programmable and recoverable shapes was printed using the $\mathrm{NaCl}$ crystal as model geometry. The as-printed object was deformed upon heating $\left(\sim 80^{\circ} \mathrm{C}\right)$, and fixed to a temporary shape after cooling to $-20^{\circ} \mathrm{C}$. The shape recovery was then triggered by placing the deformed model in a glass vial that was heated up with a heating gun. As shown in Figure 4, the deformed structure fully recovered its original shape within $30 \mathrm{~s}$.

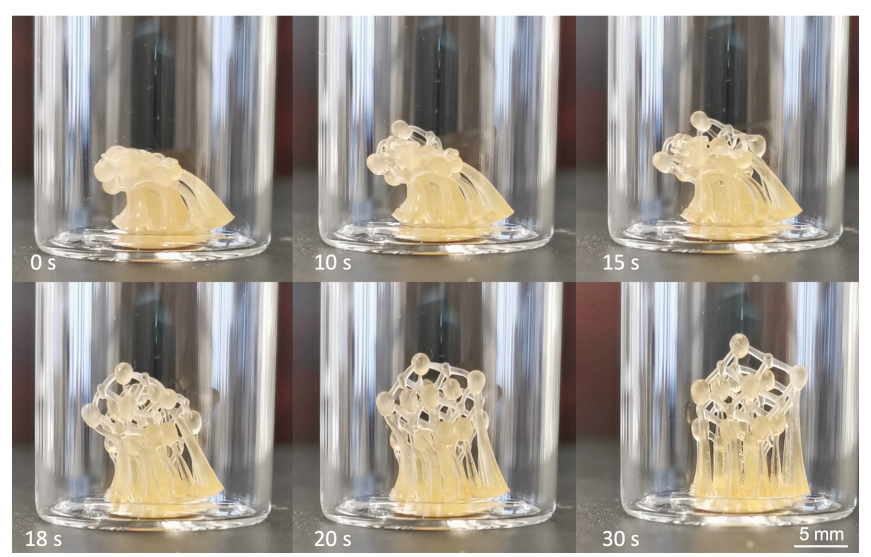

Figure 4. $\mathrm{NaCl}$ crystal model printed by DLP with P1-PCLMA reverting to its original shape upon heating to $\sim 80^{\circ} \mathrm{C}$. The initial object (at $0 \mathrm{~s}$ ) was deformed at $\sim 80^{\circ} \mathrm{C}$ and fixed in that shape by cooling to $-20^{\circ} \mathrm{C}$.

In summary, we developed BAPO-derived biodegradable polymeric photoinitiators for vat photopolymerization 3D printing. Because of their liquid form at room temperature, these initiators are easily miscible with $3 \mathrm{D}$ printing macromonomers and can be used for digital light 3D printing of biodegradable devices without the addition of organic solvents or diluents. High resolution and surface quality were achieved for all the printed objects. By ringopening copolymerization of different monomers from BAPO molecules, various biodegradable polymeric photoinitiators could, in the future, be synthesized and combined to different biodegradable polymer systems for solvent-free $3 D$ printing by SLA, DLP, continuous liquid interface production (CLIP), volumetric printing, and beyond. This work opens new perspectives for the solvent-free 3D printing of functional devices, especially for functional bioresorbable implants and scaffolds.

\section{Acknowledgements}

This project was financed by the Swiss National Science Foundation (Sinergia No. 177178). Prof. Renato Zenobi is 
acknowledged for offering the access to the MALDI-TOF/TOF-MS in his group.

Keywords: 3D printing $\cdot$ polymeric photoinitiators $\cdot$ digital light processing $\bullet$ biodegradable polymers $\bullet$ medical devices

[1] M. Guvendiren, J. Molde, R. M. D. Soares, J. Kohn, ACS Biomater. Sci. Eng. 2016, 2, 1679-1693.

[2] A. V. Do, B. Khorsand, S. M. Geary, A. K. Salem, Adv. Healthc. Mater. 2015, 4, 1742-1762.

[3] H. Ragelle, M. W. Tibbitt, S. Y. Wu, M. A. Castillo, G. Z. Cheng, S P. Gangadharan, D. G. Anderson, M. J. Cima, R. Langer, Nat. Commun. 2018, 9, 1-10.

[4] R. J. Mondschein, A. Kanitkar, C. B. Williams, S. S. Verbridge, T. E. Long, Biomaterials 2017, 140, 170-188.

[5] J. Goole, K. Amighi, Int. J. Pharm. 2016, 499, 376-394.

[6] K. Liang, S. Carmone, D. Brambilla, J. C. Leroux, Sci. Adv. 2018, 4, $1-12$.

[7] H. J. Oh, M. S. Aboian, M. Y. J. Yi, J. A. Maslyn, W. S. Loo, X. Jiang, D. Y. Parkinson, M. W. Wilson, T. Moore, C. R. Yee, G. R. Robbins, F. M. Barth, J. M. Desimone, S. W. Hetts, N. P. Balsara, ACS Cent. Sci. 2019, 5, 419-427.

[8] T. J. Wallin, J. Pikul, R. F. Shepherd, Nat. Rev. Mater. 2018, 3, 84100.

[9] T. Y. Huang, M. S. Sakar, A. Mao, A. J. Petruska, F. Qiu, X. B. Chen, S. Kennedy, D. Mooney, B. J. Nelson, Adv. Mater. 2015, 27, 6644-6650.

[10] E. Sachyani Keneth, A. Kamyshny, M. Totaro, L. Beccai, S. Magdassi, Adv. Mater. 2020, 2003387, 1-17.

[11] N. Nagarajan, A. Dupret-Bories, E. Karabulut, P. Zorlutuna, N. E. Vrana, Biotechnol. Adv. 2018, 36, 521-533.

[12] H. H. Hwang, W. Zhu, G. Victorine, N. Lawrence, S. Chen, Small Methods 2018, 2, 1-18

[13] J. U. Lind, T. A. Busbee, A. D. Valentine, F. S. Pasqualini, H. Yuan, M. Yadid, S. J. Park, A. Kotikian, A. P. Nesmith, P. H. Campbell, J. J. Vlassak, J. A. Lewis, K. K. Parker, Nat. Mater. 2017, 16, 303308.

[14] N. Bhattacharjee, C. Parra-Cabrera, Y. T. Kim, A. P. Kuo, A. Folch, Adv. Mater. 2018, 30, 1-7.

[15] N. A. Chartrain, C. B. Williams, A. R. Whittington, Acta Biomater. 2018, 74, 90-111.

[16] F. P. W. Melchels, J. Feijen, D. W. Grijpma, Biomaterials 2010, 31 , 6121-6130.

[17] A. Bagheri, J. Jin, ACS Appl. Polym. Mater. 2019, 1, 593-611.

[18] C. Yu, J. Schimelman, P. Wang, K. L. Miller, X. Ma, S. You, J. Guan, B. Sun, W. Zhu, S. Chen, Chem. Rev. 2020, 120, 1069510743

[19] M. Layani, X. Wang, S. Magdassi, Adv. Mater. 2018, 30, 1-7.

[20] K. Seidler, M. Griesser, M. Kury, R. Harikrishna, P. Dorfinger, T. Koch, A. Svirkova, M. Marchetti-Deschmann, J. Stampfl, N. Moszner, C. Gorsche, R. Liska, Angew. Chem. Int. Ed. 2018, 57, 9165-9169; Angew. Chem. 2018, 130, 9305-9310.

[21] Z. Zhang, N. Corrigan, A. Bagheri, J. Jin, C. Boyer, Angew. Chem. Int. Ed. 2019, 58, 17954-17963; Angew. Chem. 2019, 131, 1812218131.

[22] J. J. Schwartz, A. J. Boydston, Nat. Commun. 2019, 10, 1-10.

[23] B. Zhang, K. Kowsari, A. Serjouei, M. L. Dunn, Q. Ge, Nat.
Commun. 2018, 9, 1831.

[24] N. D. Dolinski, Z. A. Page, E. B. Callaway, F. Eisenreich, R. V. Garcia, R. Chavez, D. P. Bothman, S. Hecht, F. W. Zok, C. J. Hawker, Adv. Mater. 2018, 30, 1-6.

[25] X. Kuang, J. Wu, K. Chen, Z. Zhao, Z. Ding, F. Hu, D. Fang, H. J. Qi, Sci. Adv. 2019, 5, 1-10

[26] D. G. Moore, L. Barbera, K. Masania, A. R. Studart, Nat. Mater. 2020, 19, 212-217.

[27] J. R. Tumbleston, D. Shirvanyants, N. Ermoshkin, R. Janusziewicz, A. R. Johnson, D. Kelly, K. Chen, R. Pinschmidt, J. P. Rolland, A. Ermoshkin, E. T. Samulski, J. M. DeSimone, Science 2015, 347, 1349-1352.

[28] B. E. Kelly, I. Bhattacharya, H. Heidari, M. Shusteff, C. M. Spadaccini, H. K. Taylor, Science 2019, 363, 1075-1079.

[29] D. Loterie, P. Delrot, C. Moser, Nat. Commun. 2020, 11, 1-6.

[30] R. R. Jose, M. J. Rodriguez, T. A. Dixon, F. Omenetto, D. L. Kaplan, ACS Biomater. Sci. Eng. 2016, 2, 1662-1678.

[31] J. Zhang, P. Xiao, Polym. Chem. 2018, 9, 1530-1540.

[32] E. A. Guzzi, M. W. Tibbitt, Adv. Mater. 2020, 32, 1-24.

[33] K. S. Lim, J. H. Galarraga, X. Cui, G. C. J. Lindberg, J. A. Burdick, T. B. F. Woodfield, Chem. Rev. 2020, 120, 10662-10694.

[34] S. C. Ligon, R. Liska, J. Stampfl, M. Gurr, R. Mülhaupt, Chem. Rev. 2017, 117, 10212-10290.

[35] F. P. W. Melchels, J. Feijen, D. W. Grijpma, Biomaterials 2009, 30, 3801-3809.

[36] T. M. Seck, F. P. W. Melchels, J. Feijen, D. W. Grijpma, J. Control. Release 2010, 148, 34-41.

[37] L. Elomaa, S. Teixeira, R. Hakala, H. Korhonen, D. W. Grijpma, J. V. Seppälä, Acta Biomater. 2011, 7, 3850-3856.

[38] B. J. Green, K. S. Worthington, J. R. Thompson, S. J. Bunn, M. Rethwisch, E. E. Kaalberg, C. Jiao, L. A. Wiley, R. F. Mullins, E. M. Stone, E. H. Sohn, B. A. Tucker, C. A. Guymon, Biomacromolecules 2018, 19, 3682-3692.

[39] M. Zarek, M. Layani, I. Cooperstein, E. Sachyani, D. Cohn, S. Magdassi, Adv. Mater. 2016, 28, 4449-4454.

[40] J. A. Wilson, D. Luong, A. P. Kleinfehn, S. Sallam, C. Wesdemiotis, M. L. Becker, J. Am. Chem. Soc. 2018, 140, 277-284.

[41] G. Le Fer, Y. Luo, M. L. Becker, Polym. Chem. 2019, 10, 46554664.

[42] Y. Luo, G. Le Fer, D. Dean, M. L. Becker, Biomacromolecules 2019 20, 1699-1708.

[43] M. Popal, J. Volk, G. Leyhausen, W. Geurtsen, Dent. Mater. 2018, 34, 1783-1796.

[44] A. Beil, F. A. Steudel, C. Bräuchle, H. Grützmacher, L. Möckl, Sci. Rep. 2019, 9, 1-11.

[45] J. Zhou, X. Allonas, A. Ibrahim, X. Liu, Prog. Polym. Sci. 2019, 99, 101165.

[46] Y. Han, F. Wang, C. Y. Lim, H. Chi, D. Chen, F. Wang, X. Jiao, ACS Appl. Mater. Interfaces 2017, 9, 32418-32423.

[47] J. Wang, A. Chiappone, I. Roppolo, F. Shao, E. Fantino, M. Lorusso, D. Rentsch, K. Dietliker, C. F. Pirri, H. Grützmacher, Angew. Chem. Int. Ed. 2018, 57, 2353-2356; Angew. Chem. 2018, 130, 2377-2380.

[48] J. Wang, S. Stanic, A. A. Altun, M. Schwentenwein, K. Dietliker, L. Jin, J. Stampfl, S. Baudis, R. Liska, H. Grützmacher, Chem. Commun. 2018, 54, 920-923.

[49] X. Zhang, S. Keck, Y. Qi, S. Baudis, Y. Zhao, ACS Sustain. Chem. 
Eng. 2020, 8, 10959-10970.

[50] J. Wang, Synthesis and Application of Bis(acyl)phosphane Oxide Photoinitiators, PhD thesis, ETH Zurich, 2017.

[51] B. G. Amsden, M. Yat Tse, N. D. Turner, D. K. Knight, S. C. Pang, Biomacromolecules 2006, 7, 365-372.

[52] T. Kuhnt, R. M. García, S. Camarero - Espinosa, A. Dias, A. T. ten Cate, C. A. van Blitterswijk, L. Moroni, M. B. Baker, Biomater. Sci. 2019, 7, 4984-4989.

[53] N. Paunović, Y. Bao, F. B. Coulter, K. Masania, A. Karoline, K. Klein, A. Rafsanjani, J. Cadalbert, P. W. Kronen, A. Karol, Z. Luo, F. Rüber, D. Brambilla, B. Von, D. Franzen, A. R. Studart, J. C. Leroux, bioRxiv, 2020, DOI 10.1101/2020.09.12.294751.

[54] H. M. Younes, E. Bravo-Grimaldo, B. G. Amsden, Biomaterials 2004, 25, 5261-5269.

[55] M. O. Wang, J. M. Etheridge, J. A. Thompson, C. E. Vorwald, D. Dean, J. P. Fisher, Biomacromolecules 2013, 14, 1321-1329.

[56] Y. Zhang, L. Huang, H. Song, C. Ni, J. Wu, Q. Zhao, T. Xie, ACS Appl. Mater. Interfaces 2019, 11, 32408-32413.

[57] X. Kuang, D. J. Roach, J. Wu, C. M. Hamel, Z. Ding, T. Wang, M. L. Dunn, H. J. Qi, Adv. Funct. Mater. 2019, 29, 1-23. 


\section{Entry for the Table of Contents}

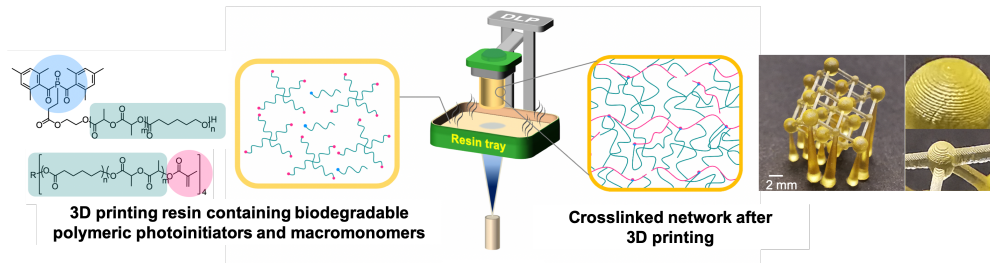

Biodegradable polymeric photoinitiators were developed for solvent-free 3D printing of biodegradable materials based on vat photopolymerization. The polymeric photoinitiators are liquid at room temperature and easily miscible with biodegradable photopolymers, enabling high-quality 3D printing of complex architectures, including biodegradable shape memory structures.

Institute and researcher Twitter usernames: @ETH_DCHAB and @Yinyin_Bao 


\section{Supporting information}

for

\section{Solvent-Free 3D Printing Based on Biodegradable Polymeric Photoinitiators}

Matthias Sandmeier," ${ }^{[a]}$ Nevena Paunović, ${ }^{[[a]}$ Riccardo Conti, ${ }^{[b]}$ Leopold Hofmann, ${ }^{[a]}$ Jieping Wang, ${ }^{[b]}$ Zhi Luo, ${ }^{[\mathrm{a}]}$ Kunal Masania, ${ }^{[\mathrm{c}, \mathrm{d}]} \mathrm{Na}$ Wu, ${ }^{[\mathrm{e}]}$ Nicole Kleger, ${ }^{[\mathrm{c}]}$ Fergal Brian Coulter, ${ }^{[\mathrm{c}]}$ André R. Studart, ${ }^{[\mathrm{c}]}$ Hansjörg Grützmacher, ${ }^{[b]}$ Jean-Christophe Leroux*[a], Yinyin Bao*[a]

[a] Institute of Pharmaceutical Sciences, Department of Chemistry and Applied Biosciences, ETH Zurich. Vladimir-Prelog-Weg 1-5/10, 8093 Zurich, Switzerland. E-Mail: jleroux@ethz.ch; yinyin.bao@pharma.ethz.ch

[b] Laboratory of Inorganic Chemistry, Department of Chemistry and Applied Biosciences. ETH Zurich. Vladimir-Prelog-Weg 1-5/10, 8093 Zurich, Switzerland

[c] Complex Materials, Department of Materials, ETH Zurich. Vladimir-Prelog-Weg 1-5/10, 8093 Zurich, Switzerland

[d] Present address: Shaping Matter Lab, Faculty of Aerospace, TU Delft, Netherlands

[e] Lab of Organic Chemistry, Department of Chemistry and Applied Biosciences, ETH Zurich, Vladimir-Prelog-Weg 1-5/10, 8093 Zurich, Switzerland

\# The authors contributed equally

\section{Materials and Methods}

\section{Materials}

Unless stated otherwise, all reagents were used as received without further purification. Pentaerythritol, methacryloyl chloride, trimethylamine, tetrahydrofuran (THF, extra dry) and acetone (extra dry) were purchased from Acros Organics. $\varepsilon$-Caprolactone $(C L)$ was obtained from Tokyo Chemical Industry. 3,6-dimethyl-1,4-dioxane-2,5-dione (D,L-lactide, DLLA) was purchased from Huizhou Foryou Medical Devices Co., Ltd. or Acros Organics. Tin(II)-2-ethylhexanoate (Sn(Oct)2), 2,2-diethyl-1,3-propanediol, sodium bicarbonate $\left(\mathrm{NaHCO}_{3}\right)$, sodium chloride ( $\left.\mathrm{NaCl}\right),(+)$ - $\alpha$-tocopherol (vitamin $\left.\mathrm{E}\right)$, phenylbis(2,4,6trimethyl-benzoyl)phosphine oxide (BAPO), 1-(phenyldiazenyl)naphthalen-2-ol (Sudan I), and lithium bromide $(\mathrm{LiBr})$ were purchased from Sigma Aldrich. Hexane, dichloromethane (DCM) and dimethylformamide (DMF) were purchased from Fisher Scientific. Dimethyl sulfoxide-d6 (DMSO-d6) was obtained from ReseaChem. Methanol and 2-propanol were provided by VWR Chemicals. PBS was obtained from Thermo Fisher Scientific. BAPO-HEA and BAPO-DIOL were synthesized according to the reported methods. ${ }^{[1],[2]}$

\section{Polymer synthesis}

Poly(DLLA-co-CL) MA (MM1k-P9k) were synthesized by ring-opening polymerization of DLLA and CL initiated by pentaerythritol (4-arm structure) with $\mathrm{Sn}(\mathrm{Oct})_{2}$ as a catalyst, and post-functionalization with methacryloyl chloride, according to the reported method. ${ }^{[3]}$ The molecular weight of the polymers was controlled by varying the molar feed ratio of the monomers and initiators $([\mathrm{M}] /[\mathrm{I}])$. 
BAPO polymers were synthesized by ring-opening polymerization of DLLA and CL initiated by BAPOHEA or BAPO-DIOL with $\mathrm{Sn}(\mathrm{Oct})_{2}$ as a catalyst. The molecular weight of the polymers was controlled by varying the molar feed ratio of the monomers and initiators $([\mathrm{M}] /[\mathrm{I}])$.

Synthesis of P1. BAPO-HEA (0.5 g, $1.09 \mathrm{mmol}), \mathrm{CL}(1.24 \mathrm{~g}, 10.9 \mathrm{mmol})$ and DLLA (1.57 g, $10.9 \mathrm{mmol})$ were added to a Schlenk flask. The flask was exposed to vacuum for $1 \mathrm{~h}$ and purged with argon for three cycles to remove water and oxygen. $\mathrm{Sn}(\mathrm{Oct})_{2}(3.3 \mu \mathrm{L}, 0.01 \mathrm{mmol})$ was dissolved in toluene $(3 \mathrm{~mL})$ in another flask and purged with argon for $15 \mathrm{~min}$. The solution was injected to the monomer mixture under argon atmosphere, and the Schlenk flask was then placed in an oil bath at $90^{\circ} \mathrm{C}$ for $72 \mathrm{~h}$ under stirring. The product was dissolved in THF and precipitated in hexane, resulting in a light yellow and highly viscous polymer $\mathrm{P} 1$.

Synthesis of P2. BAPO-DIOL (0.24 g, $0.5 \mathrm{mmol}), \mathrm{CL}(0.4 \mathrm{~g}, 3.5 \mathrm{mmol})$ and DLLA (0.22 g, $1.5 \mathrm{mmol})$ were added to a Schlenk flask. The flask was exposed to vacuum for $1 \mathrm{~h}$ and purged with argon for three cycles to remove water and oxygen. $\mathrm{Sn}(\mathrm{Oct})_{2}(2.0 \mu \mathrm{L}, 0.006 \mathrm{mmol})$ was dissolved in toluene $(1.8 \mathrm{~mL})$ in another flask and purged with argon for $15 \mathrm{~min}$. The solution was injected to the monomer mixtures under argon atmosphere, and the Schlenk flask was then placed in an oil bath at $80^{\circ} \mathrm{C}$ for $24 \mathrm{~h}$ under stirring. The product was dissolved in THF and precipitated in hexane, resulting in a light yellow and highly viscous polymer P2.

\section{Polymer Characterization}

${ }^{1} \mathrm{H}$ NMR spectra were recorded on Bruker AV400 spectrometer at $400 \mathrm{~Hz}$ using DMSO-d6 as a solvent. Size exclusion chromatography (SEC) was carried out on a Viscotek TDAmax system equipped with two Viscotek columns (D3000, poly(styrene-co-divinylbenzene)) and differential refractive index detector (TDA 302, Viskotek). All samples were dissolved in DMF, filtered using 0.2- $\mu \mathrm{m}$ syringe filters (polytetrafluoroethylene, PTFE) and eluted using DMF with $\mathrm{LiBr}(0.1 \mathrm{wt} \%$ ) as a mobile phase (mobile phase flow: $\left.0.5 \mathrm{~mL} \mathrm{~min}^{-1}\right)$. The macromolecular characteristics were determined relative to a poly(methyl methacrylate) (PMMA) standard curve (PSS polymer Mainz, 2500-89,300 $\mathrm{g} \mathrm{mol}^{-1}$ ). Differential scanning calorimetry (DSC) analysis was performed using TA Q200 DSC (TA InstrumentsWaters LLC). The samples (ca. $10 \mathrm{mg}$ ) were placed on Tzero hermetic pans (TA Instruments-Waters LLC) and exposed to heat-cool-heat cycles from -80 to $200^{\circ} \mathrm{C}$ under nitrogen flow (50 $\mathrm{mL} \mathrm{min}^{-1}$ ) using heating and cooling rates of $10^{\circ} \mathrm{C} \mathrm{min}{ }^{-1}$. Data were analyzed using TA Instruments Universal Analysis 2000 software (5.5.3). Fourier-transform infrared (FTIR) spectra were recorded on a Perkin-Elmer Spectrum 65 (Perkin-Elmer Corporation) in transmission mode in the range of 600 to $4000 \mathrm{~cm}^{-1}$. Mass spectra were measured on a commercial ABSciex MALDI 4800 TOF/TOF mass spectrometer in positive linear mode using cyano-hydroxy cinnamic acid as a matrix. 


\section{DLP 3D printing}

DLP resins were prepared by mixing the macromonomers (MM1k-9k), BAPO polymeric photoinitiators $(1.0-2.3 w t \%)$, Sudan I $(0.03 \mathrm{wt} \%)$ and vitamin $\mathrm{E}(0.3 \mathrm{wt} \%)$. The resins were sonicated at $60{ }^{\circ} \mathrm{C}$ until homogenous mixture was obtained. A commercial DLP 3D printer (Asiga PICO2) comprising the LED light source of $405 \mathrm{~nm}$ with customized resin tray and printing head with heating functions, was used to fabricate all the objects. ${ }^{[3]}$ The printing was performed at temperature of $90{ }^{\circ} \mathrm{C}$, with layer thickness of $50 \mu \mathrm{m}$ and exposure time of 3-4 s. The light intensity of the printer LED was $25.67 \mathrm{~mW} / \mathrm{cm}^{2}$. After the printing, the printed objects were cleaned in acetone and 2-propanol, and then cured in an Asiga Pico Flash UV chamber for $15 \mathrm{~min}$.

\section{Curing test}

The 3D printing resin was irradiated with a round spot shape LED light $(405 \mathrm{~nm})$ on the 3D printer with different exposure times ranged from 2 to $20 \mathrm{~s}$, and the thickness of the crosslinked layer was measured using a caliper. Penetration depth $\left(D_{p}\right)$ was calculated according to the Jacobs' equation based on BeerLambert law ${ }^{[4]}$ (Equation 1):

$$
C_{d}=D_{p} \ln \left[\frac{E_{0}}{E_{c}}\right]
$$

where $C_{\mathrm{d}}$ is the depth/thickness of cured resin, $E_{0}$ is the energy of light at the surface, and $E_{\mathrm{c}}$ is the "critical" energy required to initiate polymerization. A semilog plot of $C_{d}$ vs. $E_{0}$ produces a straight-line curve with a slope of $D_{\mathrm{p}}$ and a x-intercept of $E_{\mathrm{c}}$. Exposure time was chosen based on $D_{\mathrm{p}}$ and $E_{\mathrm{c}}$ related to the desired part properties.

\section{Mechanical test}

Tensile and compression tests were performed using an AGS-X (Shimadzu) universal testing machine with a 100-N capacity load cell. Tensile tests were carried out on dog-bone shaped 3D printed specimens (ASTM 638 type IV) with a gauge length of $13 \mathrm{~mm}$ at a rate of $20 \mathrm{~mm} \mathrm{~min}^{-1}$. Every material was tested in sextuplicates. Compression tests were performed on tubular $3 \mathrm{D}$ printed specimens (H $10.0 \mathrm{~mm}, \varnothing 8.0 \mathrm{~mm}$, thickness 1.0 ) at a rate of $10 \mathrm{~mm} \mathrm{~min}^{-1}$ with three compressions per sample. ${ }^{[3]}$ Young's modulus $E$ was determined as follows (Equation 2):

$$
E=\frac{\sigma}{\varepsilon}
$$

where $\sigma$ is the engineering stress and $\varepsilon$ is the engineering strain.

\section{In vitro degradation study}

Four 3D printed tubular specimens $(\mathrm{H} 10.0 \mathrm{~mm}, \varnothing 8.0 \mathrm{~mm}$, thickness $1.0 \mathrm{~mm}$ ) were immersed separately in $50 \mathrm{~mL} \mathrm{PBS} \mathrm{pH} 7.4$ at $50^{\circ} \mathrm{C}$, in glass conical flasks. The buffer was replaced weekly. For each time before the test, the specimens were taken out, rinsed with deionized water, wiped with a paper tissue and dried under vacuum at $50^{\circ} \mathrm{C}$ overnight. The water uptake (wt\%) was calculated using Equation 3: 


$$
\text { water uptake }=\frac{w t_{w e t}-w t_{d r y}}{w t_{d r y}} \times 100
$$

where $w t_{w e t}$ is the mass of a stent in a wet state after the wiping, and $w t_{d r y}$ is the mass of a stent in a dry state after drying under vacuum. The dried specimens were tested in a uniaxial compression test..$^{[3]}$

\section{Cell culture}

Human cervical epithelial cells (HeLa, ATCC) were cultured at $37^{\circ} \mathrm{C}$ in a humidified atmosphere with $5 \% \mathrm{CO}_{2}$. The cells were used up to passage number 31 and were tested for mycoplasma contamination (MycoAlertTM Mycoplasma Detection Kit, Lonza) at $10^{\text {th }}$ and last passage number. HeLa cell line was cultured in complete medium containing DMEM (high glucose, GlutaMax ${ }^{\mathrm{TM}}$, pyruvate, Thermo Fisher Scientific) supplemented with $10 \%$ fetal bovine serum (Thermo Fisher Scientific) and $1 \%$ penicillinstreptomycin (Thermo Fisher Scientific).

\section{In vitro cytocompatibility test}

The test was performed in triplicates in a 24-well plate with seeding density of 80,000 HeLa cells per well and repeated three times. As a positive control, cells were incubated in complete medium with $10 \mathrm{mM}$ hydrogen-peroxide while complete medium alone was used as a negative control. Cell viability was determined using the MTS assay (CellTiter $96^{\circledR}$ Aqueous One Solution Cell Proliferation Assay, G3580; Promega) according to the manufacturer's instructions and was calculated as a percentage of the negative control. 3D printed disks ( $\mathrm{H} 0.8 \mathrm{~mm}, \varnothing 5.5 \mathrm{~mm}$ ) were washed in acetone and then in PBS $\mathrm{pH} 7.4(50 \mathrm{~mL})$ for $30 \mathrm{~min}$ and overnight, respectively. Afterwards, the objects were dried under vacuum at room temperature for $24 \mathrm{~h}$ and then cured in an Asiga Pico Flash UV chamber for 20 min. The disks were soaked in medium $(10 \mathrm{~mL})$ for 20 min before the incubation. Immediately after cell seeding, Transwell ${ }^{\circledR}$ permeable supports (ThinCert ${ }^{\mathrm{TM}}$ Cell Culture Inserts 24 -well, sterile, translucent, pore size $8 \mu \mathrm{m}$; Greiner Bio-One) were placed in corresponding wells and 3D printed disks were placed on top of the inserts and covered with medium $(100 \mu \mathrm{L})$. The plate was incubated for $48 \pm 1 \mathrm{~h}^{\left[{ }^{[3]}\right.}$ 

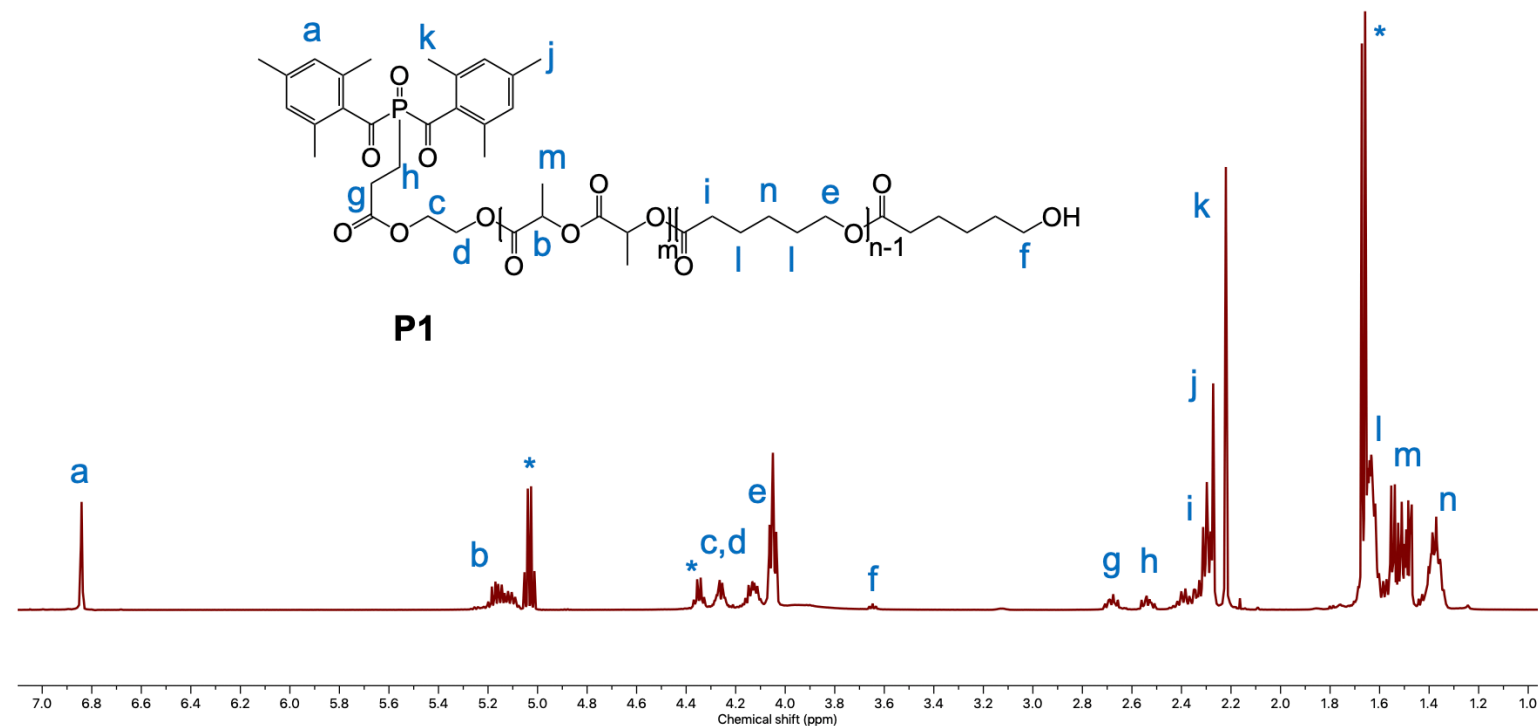

Figure S1. ${ }^{1} \mathrm{H}$ NMR spectrum of BAPO-HEA-poly(DLLA-co-CL) (P1) in $\mathrm{CDCl}_{3}$. *Free lactide signal at 5.03 and $1.66 \mathrm{ppm} ;-\mathrm{CH}-\mathrm{OH}$ of lactide when it is at the chain end at $4.35 \mathrm{ppm}$.

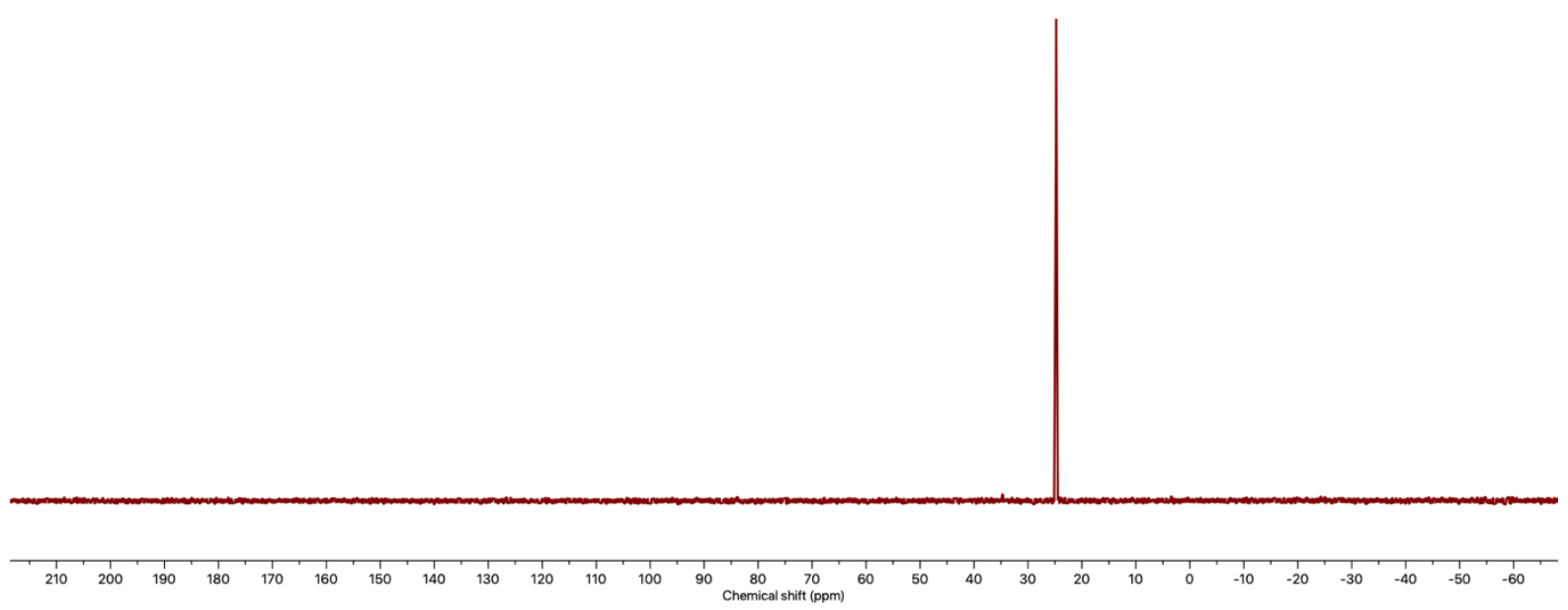

Figure S2. ${ }^{31} \mathrm{P}$ NMR spectrum of BAPO-HEA-poly(DLLA-co-CL) (P1) in $\mathrm{CDCl}_{3}$. 


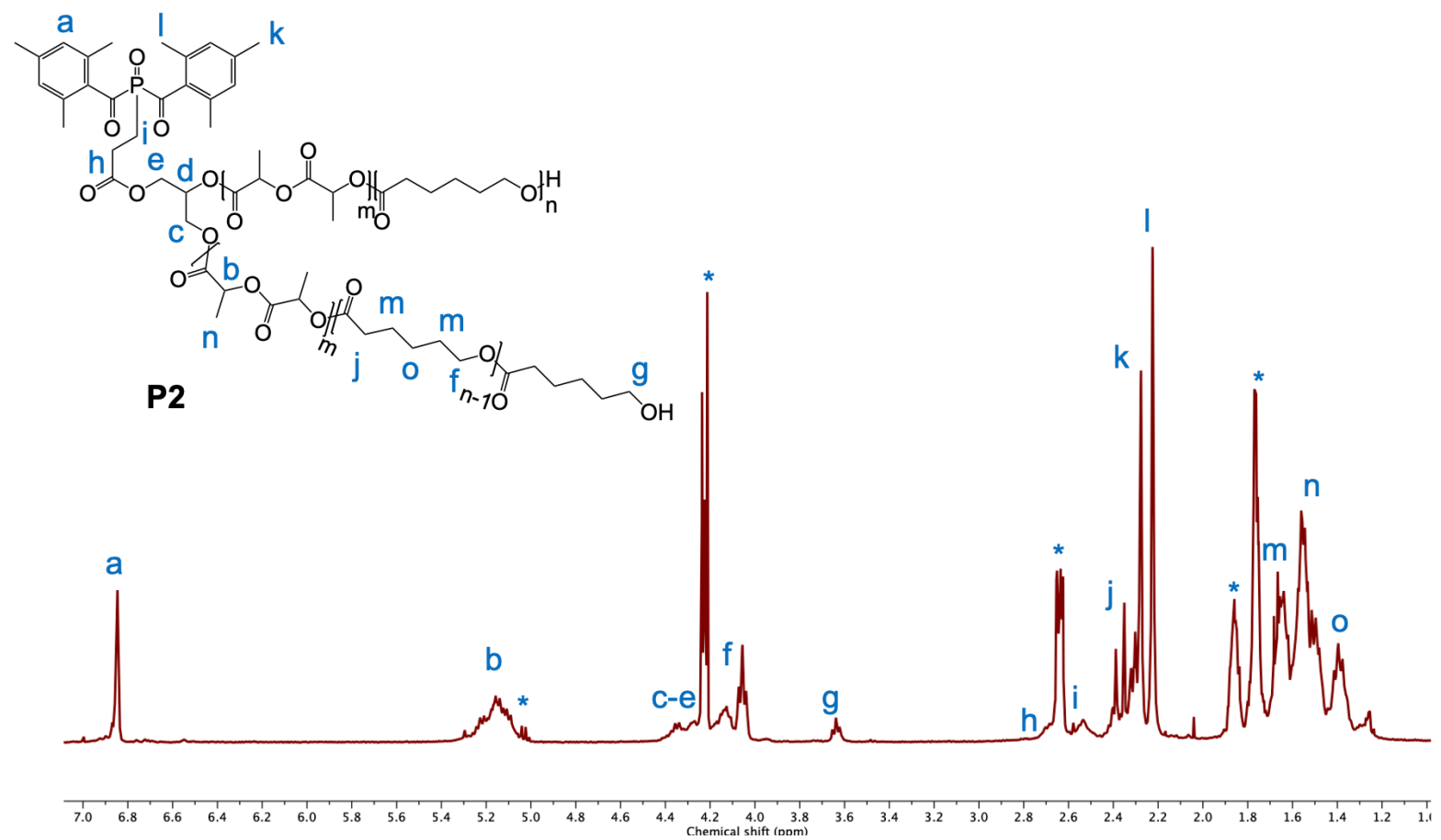

Figure S3. ${ }^{1} \mathrm{H}$ NMR spectrum of BAPO-DIOL-poly(DLLA-Co-CL) (P2) in $\mathrm{CDCl}_{3}$. ${ }^{*}$ Free DLLA signal at 5.03 and $1.66 \mathrm{ppm}$; free $\mathrm{CL}$ signal at 4.21, 2.64, 1.86 and $1.76 \mathrm{ppm}$.

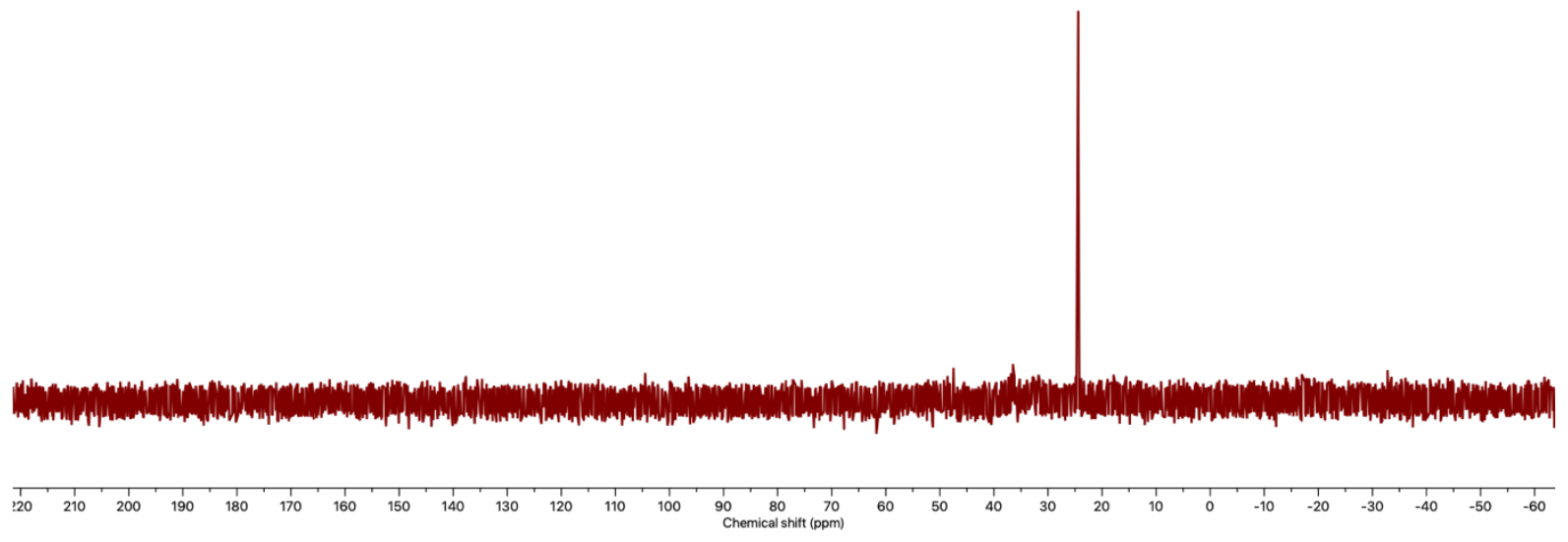

Figure S4. ${ }^{31} \mathrm{P}$ NMR spectrum of BAPO-DIOL-poly(DLLA-co-CL) (P2) in $\mathrm{CDCl}_{3}$. 
a)

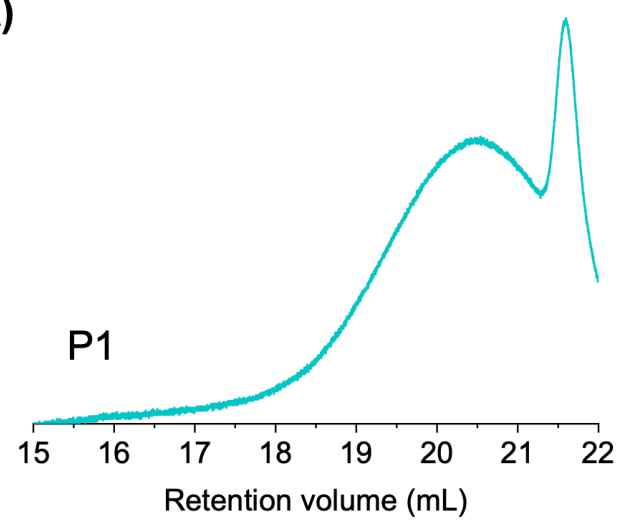

b)

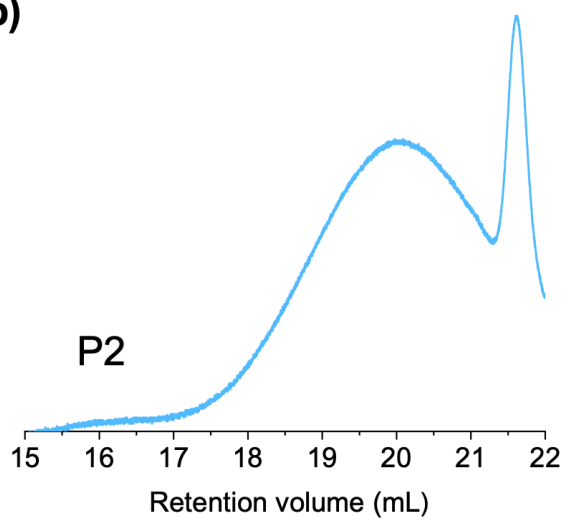

Figure S5. SEC spectra of a) P1 and b) P2 with signals overlapped with the solvent peak.

a)

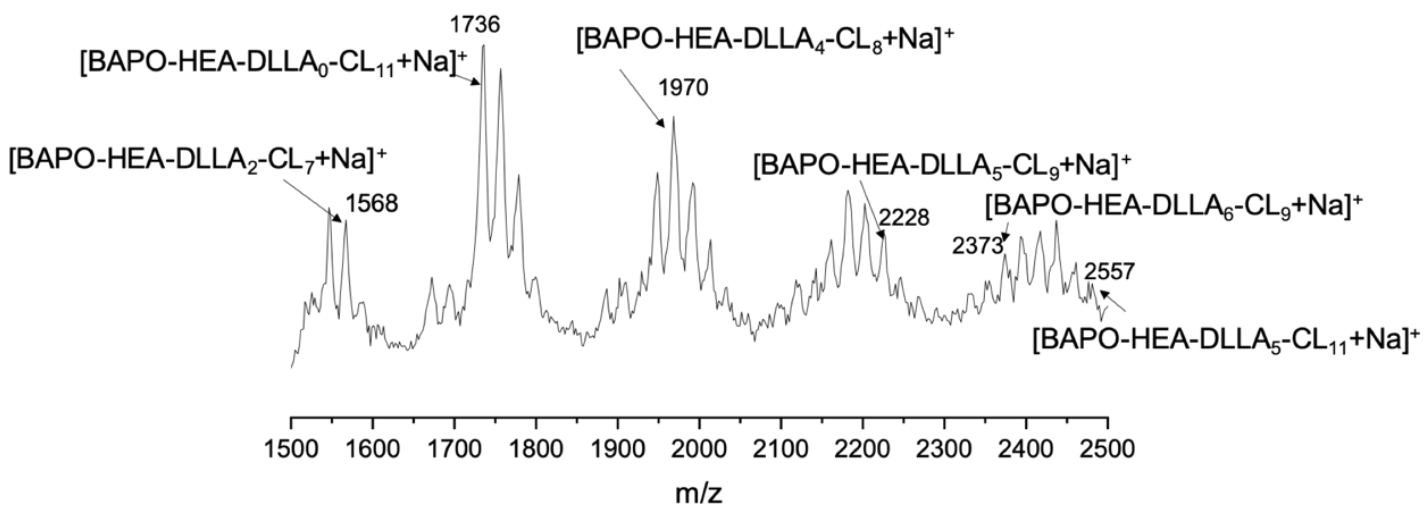

b)

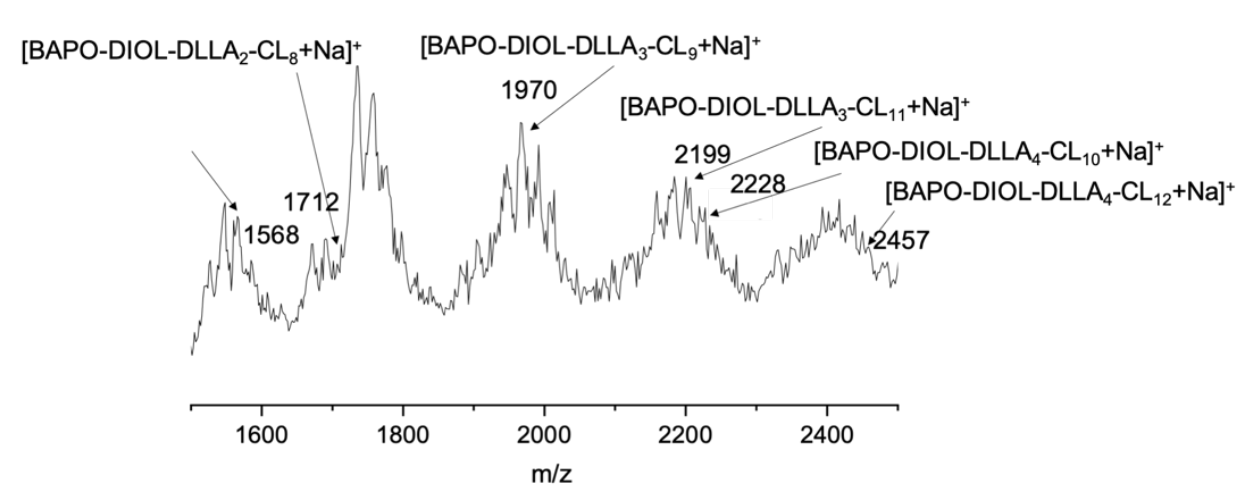

Figure S6. MALDI spectra of P1 and P2. 


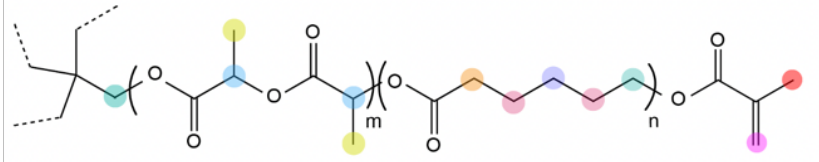

Poly(DLLA-co-CL) MA macromonomer

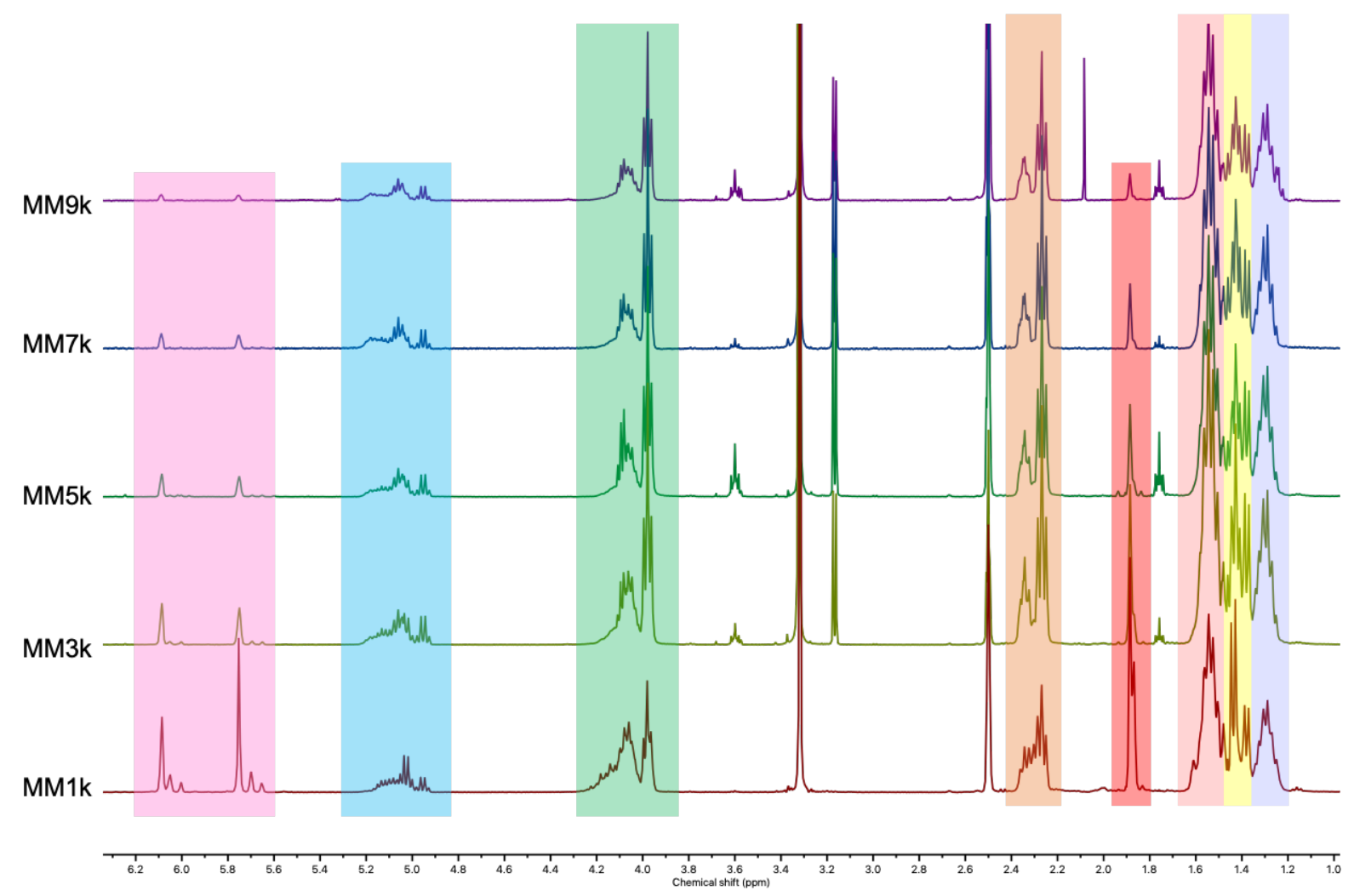

Figure S7. ${ }^{1} \mathrm{H}$ NMR spectra of poly(DLLA-Co-CL) methacrylates (P1k-P9k). Solvent: DMSO-d6. Solvent peaks appeared at $2.50 \mathrm{ppm}$ (DMSO), $3.33 \mathrm{ppm}\left(\mathrm{H}_{2} \mathrm{O}\right), 3.60$ and $1.76 \mathrm{ppm}$ (THF), and $3.16 \mathrm{ppm}$ (methanol). The molecular weights of MM1k-9k were determined by ${ }^{1} \mathrm{H}$ NMR spectroscopy yielding $1200,3000,5000,6800$ and $9100 \mathrm{~g} \mathrm{~mol}^{-1}$, from the bottom to the top.

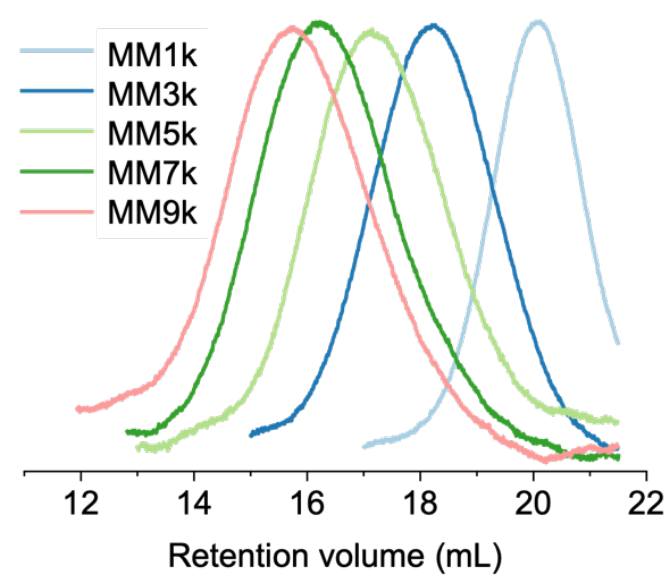

Figure S8. GPC spectra of MM1k-9k before methacrylation. 


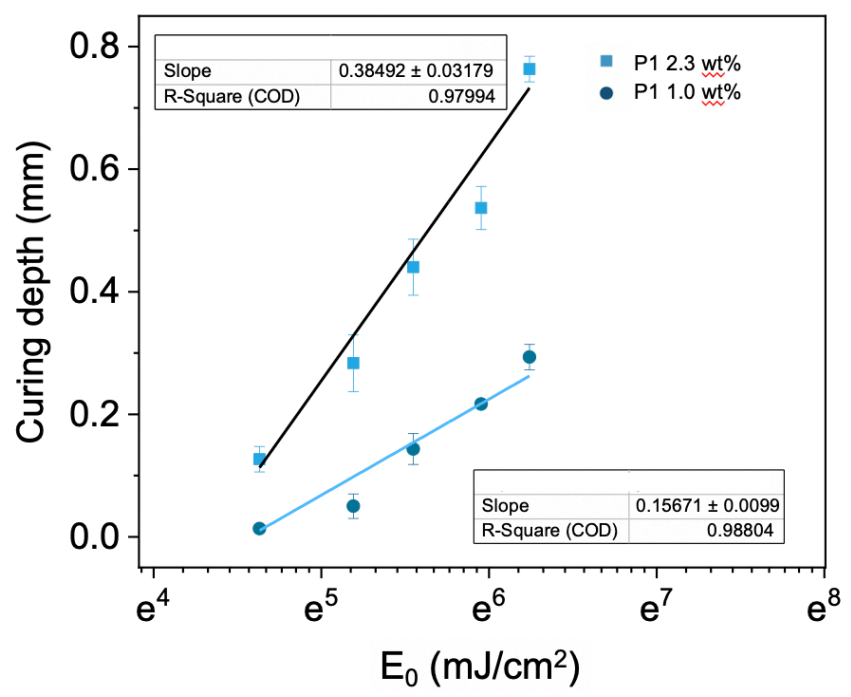

Figure S9. Curing depth-light energy relationship of the resin based on MM9k in the presence of 2.3 or $1.0 \mathrm{wt} \% \mathrm{P} 1$. The curing depth is expressed as mean \pm s.d. $(n=3)$. The slope represents the characteristic penetration depth (385 $\mu \mathrm{m}$ for $2.3 \mathrm{wt} \%$ and $157 \mu \mathrm{m}$ for $1.0 \mathrm{wt} \%$ ).

a)

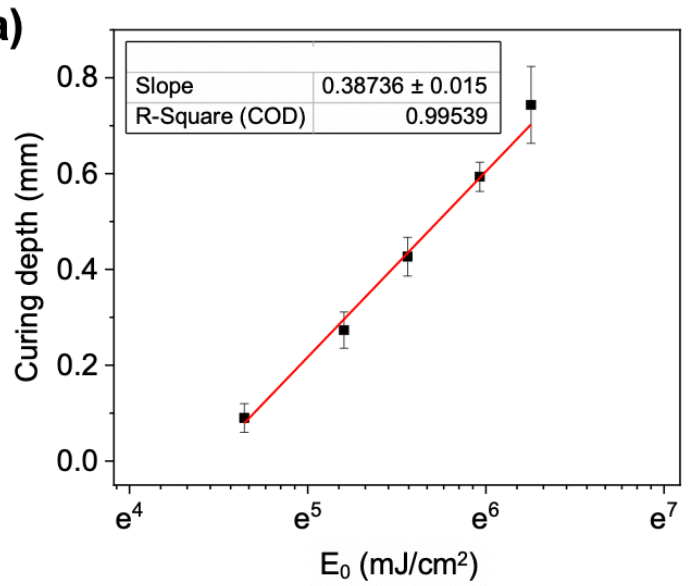

b)

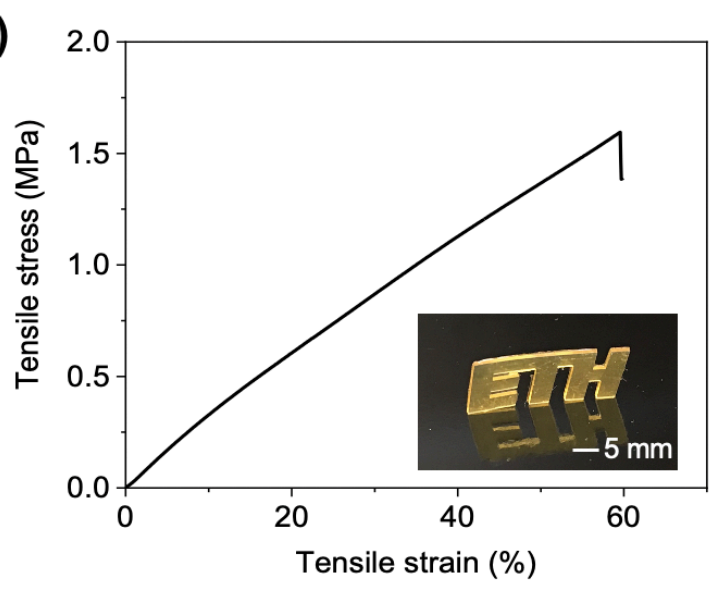

Figure S10. a) Curing depth-light energy relationship of the resin based on MM7k in the presence of $2.0 \mathrm{wt} \% \mathrm{P} 2$. The curing depth is expressed as mean \pm s.d. $(n=3)$. The slope represents the characteristic penetration depth (387 $\mu \mathrm{m}$ for $2.0 \mathrm{wt} \%$ ). b) Representative stress-strain curve from tensile test based on specimens printed with P2-MM7k (2.0 wt\% P2). Inset: photograph of 3D printed ETH logo using the same material. 
a)

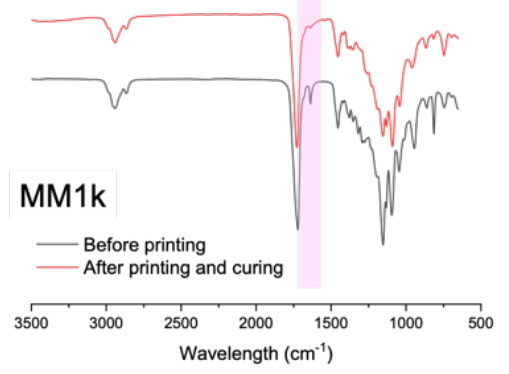

b)

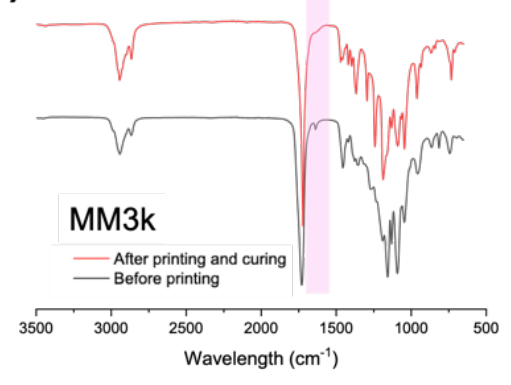

c)

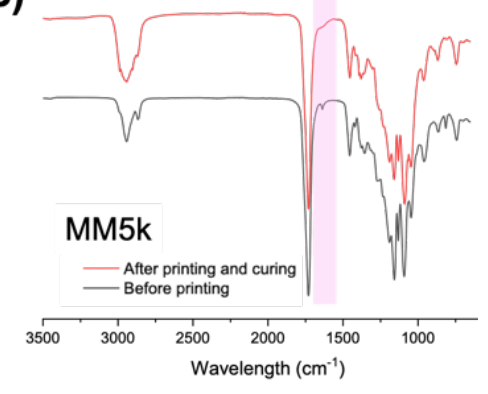

d)

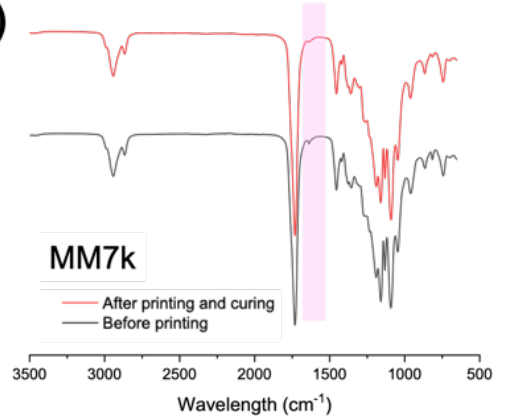

e)

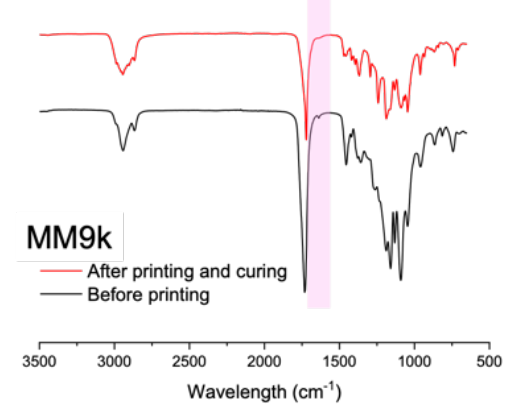

Figure S11. FTIR spectra of 3D printing resin (P1-MM1k-9k) and 3D printed tensile specimens after curing (pink band represents the peak from a vinyl group of methacrylate).

a)

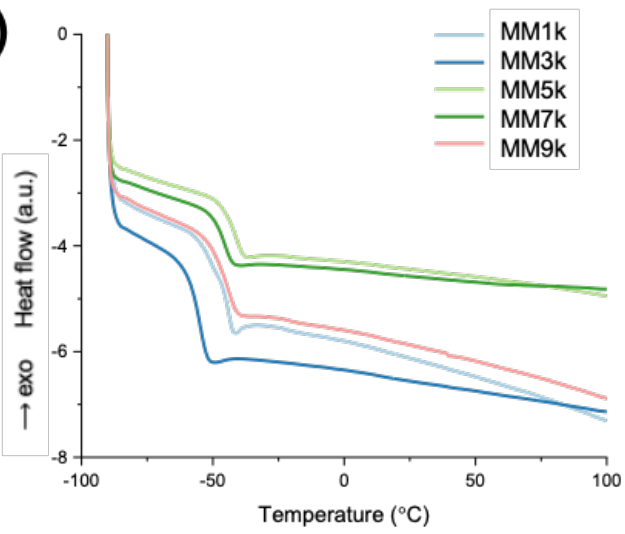

b)

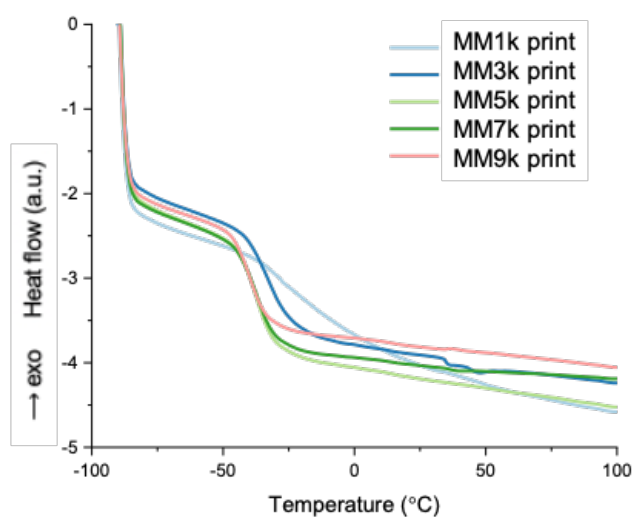

Figure S12. DSC curves of MM1k-9k and their 3D printed products using P1. 

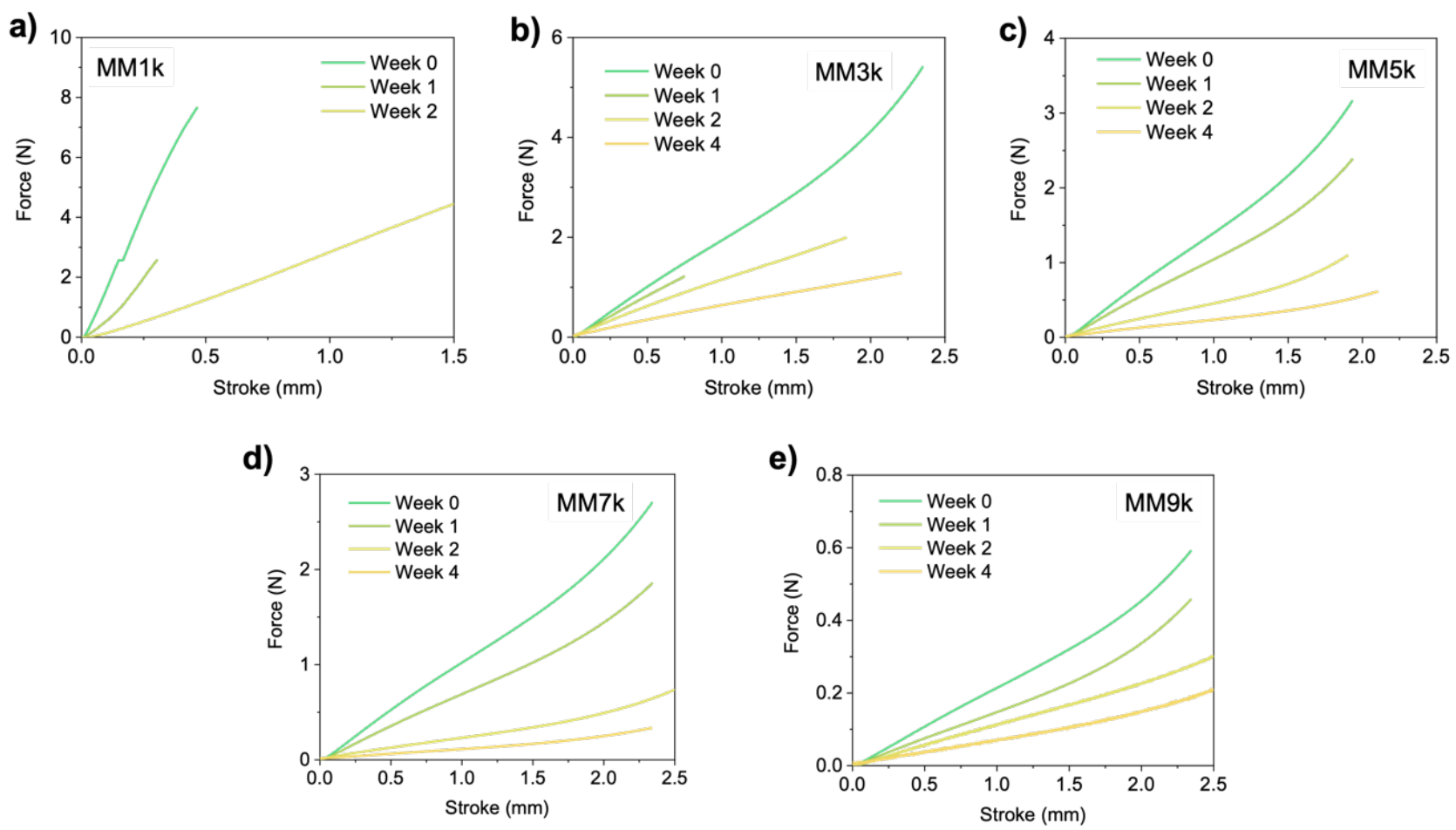

Figure S13. Representative compression curves of 3D printed tubular specimens with P1-MM1k-9k incubated at $50^{\circ} \mathrm{C}$ at different time points.
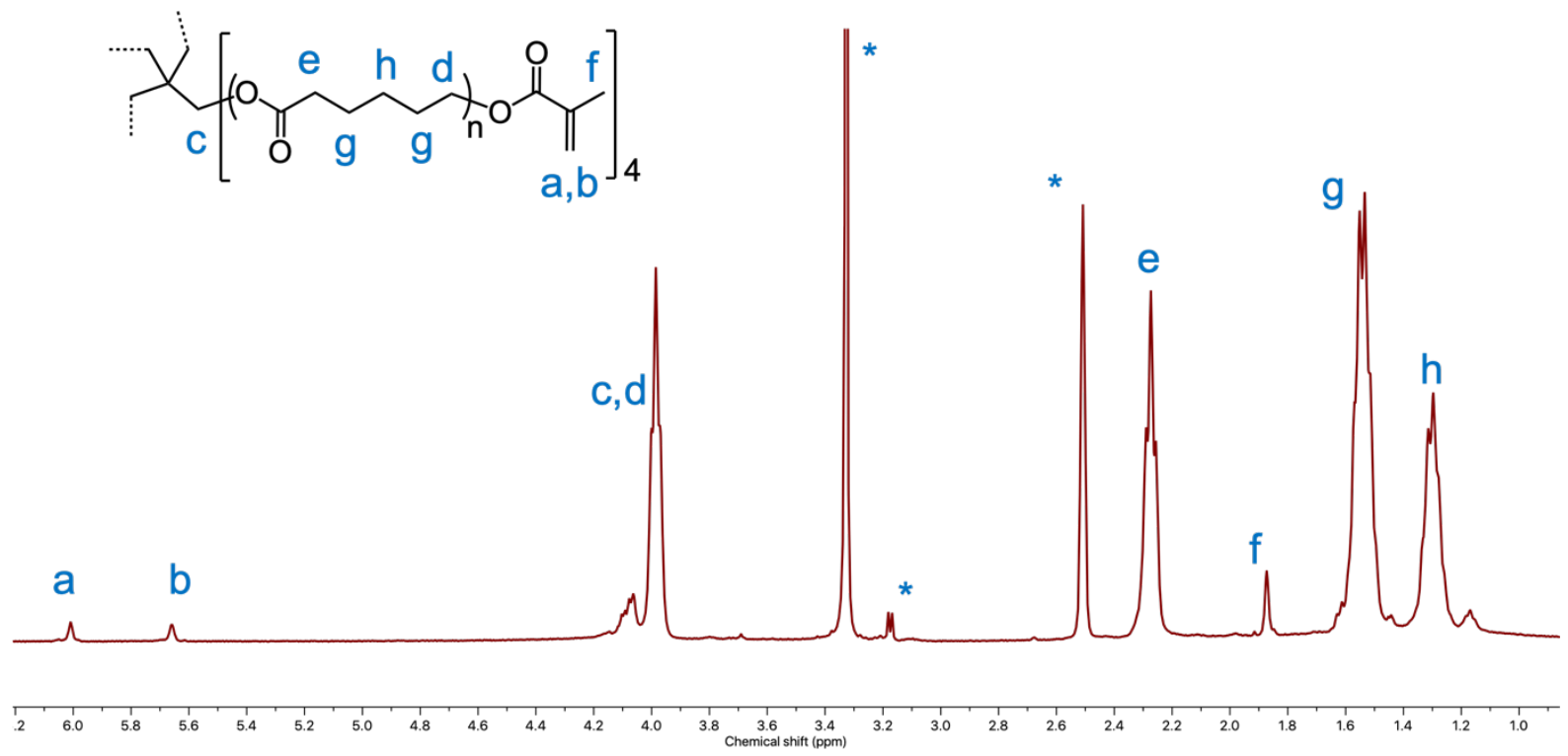

Figure S14. ${ }^{1} \mathrm{H}$ NMR spectrum of poly(e-caprolactone) methacrylate (PCLMA) in DMSO-d6. ${ }^{*} D M S O$ signal at $2.50 \mathrm{ppm}, \mathrm{H}_{2} \mathrm{O}$ signal at $3.33 \mathrm{ppm}$ and methanol signal at $3.16 \mathrm{ppm}$. 


\section{References}

[1] J. Wang, A. Chiappone, I. Roppolo, F. Shao, E. Fantino, M. Lorusso, D. Rentsch, K. Dietliker, C. F. Pirri, H. Grützmacher, Angew. Chem. Int. Ed. 2018, 57, 2353-2356; Angew. Chem. 2018, 130, 2377-2380.

[2] J. Wang, Synthesis and Application of Bis(acyl)phosphane Oxide Photoinitiators, PhD thesis, ETH Zurich, 2017.

[3] N. Paunović, Y. Bao, F. B. Coulter, K. Masania, A. Karoline, K. Klein, A. Rafsanjani, J. Cadalbert, P. W. Kronen, A. Karol, Z. Luo, F. Rüber, D. Brambilla, B. Von, D. Franzen, A. R. Studart, J. C. Leroux, bioRxiv, 2020, DOI: 10.1101/2020.09.12.294751.

[4] P. F. Jacobs, J. Manuf. Syst. 1993, 12, 430-433. 